\title{
EL DESARROLLO DE LA INDUSTRIA AZUCARERA EN EL VALLE DEL CAUCA, COLOMBIA, 1901-2015
}

\section{MARÍA TERESA RIPOLL ECHEVERRÍA*}

\section{RESUMEN}

En el transcurso del siglo xx, un grupo de empresarios agroindustriales del Valle del Cauca construyó, a través de distintas estrategias, uno de los sectores empresariales más exitosos en Colombia. Líderes en la producción azucarera, los dueños de ingenios del Valle del Cauca han expandido su portafolio de inversiones con la creación de agroindustrias en otras regiones del país y en otros países de América Latina. Hoy la industria azucarera colombiana es uno de los complejos productivos de mayor influencia en el desarrollo económico y social de la región y de Colombia. Este trabajo es una síntesis de las principales etapas que se detectan en ese desarrollo secular, subrayando aquellas estrategias que han sido claves en la productividad, el rendimiento y la sostenibilidad de industria del azúcar en el siglo XX.

Palabras clave: Industria azucarera, Valle del Cauca, agroindustrias, grupos empresariales, La Manuelita, tecnología

Clasificaciones JEL: N86, N66, N56

* La autora es profesora de la Facultad de Economía y Negocios de la Universidad Tecnológica de Bolívar en el programa de Administración de Empresas. Correo electrónico: mripoll@utb.edu.co. Este trabajo es un avance de una investigación más ambiciosa, aún en curso, sobre el Ingenio La Manuelita, pero que no se circunscribe sólo a este. Una segunda unidad de análisis incluye el tejido empresarial agroindustrial conformado por los dueños de ingenios del Valle del Cauca, y el análisis de su acción colectiva. En el curso de esta investigación he contado con el estímulo y la valiosa colaboración de Haroldo Calvo Stevenson, y con la generosa ayuda, en Palmira, del Archivo de La Manuelita y de su directora, María Teresa Salamanca. A ellos mi especial agradecimiento. Recibido: 25 de febrero de 2019; aceptado: 14 de mayo de 2019.

Economía \& Región, Vol. 13, No. 1, (Cartagena, junio 2019), pp. 87-143. 


\section{ABSTRACT \\ The Development of the Sugar Industry in Valle del Cauca, Colombia, 1901-2015}

During the Xxth century, a group of agribusiness entrepreneurs from Valle del Cauca built, using different strategies, one of the most succesful business sectors in Colombia. The owners of factories in Valle del Cauca, leaders in sugar production, have expanded their investment portfolio by creating agribusinesses in other regions of the country and in other Latin American countries. Today, the Colombian sugar industry is one of the productive complexes with the most influence over the economic and social development of Valle del Cauca and Colombia. This paper is a synthesis of the main stages in that long-term development, underlining those that have been key to the productivity, returns, and sustainability of the sugar industry in the xxth century.

Key words: Sugar industry, Valle del Cauca, agrobusinesses, business groups, La Manuelita, technology

JEL Classifications: N86, N66, N56

\section{INTRODUCCIÓN}

El objetivo central de este trabajo es indagar acerca de la formación y el desarrollo secular del sector azucarero del Valle del Cauca, visto a través del desempeño de los dueños de ingenios. Detrás de la formación de ese tejido empresarial agroindustrial ${ }^{1}$ hay más de un siglo de esfuerzos continuos de varias generaciones de azucareros que contribuyeron con su trabajo a su construcción y sostenibilidad. En los primeros años del siglo XXI estos empresarios dueños de ingenios expandieron su portafolio de inversiones a otras regiones del país y a otros países de América Latina.

\footnotetext{
${ }^{1}$ Un tejido empresarial es un sistema productivo local, “(...) formas de organizar la producción a escala local, territorial o regional.” Véase Cerutti y Carrillo (coord.), 2006, Agricultura comercial, empresa y desarrollo regional en el noroeste de México, Editorial UAS, México, p. 88.
} 
El análisis del sector azucarero tiene como hilo conductor la historia del ingenio La Manuelita, el más antiguo y de mayor influencia en el Valle del Cauca, una empresa de familia que en la actualidad es administrada por la cuarta generación de los descendientes del Fundador. La Manuelita, con más de un siglo de existencia, marcó la pauta y fue el modelo a seguir en la región. El interés principal de este estudio es ofrecer una interpretación acerca del liderazgo en la producción azucarera que esta zona del país ha mantenido en Colombia hasta hoy; se trata de una interpretación que va más allá de las ventajas comparativas que se le atribuyen al Valle del Cauca debido a las condiciones naturales excepcionales de la zona, un valle interandino en donde la caña de azúcar se cosecha los 365 días del año. ${ }^{2}$

El desarrollo del sector azucarero se concentró en este valle localizado en el suroccidente colombiano. El río Cauca lo atraviesa de sur a norte. Tiene una extensión de 456.500 hectáreas, de las cuales aproximadamente la mitad está sembrada en caña. El Valle del Cauca es el segundo departamento más poblado de Colombia con 4.613 .000 habitantes (2015). Está conformado por 42 municipios, siendo su capital Cali la tercera ciudad más grande en Colombia. En 2015 había 13 ingenios en la zona, propietarios del 25 por ciento del total del área sembrada en caña. El restante 75 por ciento pertenece a cultivadores independientes, proveedores de caña a los ingenios. En 2015 la producción total de azúcar fue de 2.398.077 t.m.v.c., ${ }^{3}$ de las cuales 1.600 .000 se vendieron en el mercado interno, y 795.000 t.m. se exportaron a Estados Unidos y a seis países de América Latina.

La principal fuente primaria usada en esta investigación ha sido el archivo de La Manuelita, abierto al público recientemente. El comportamiento del sector azucarero de la región es visible en esta documentación puesto que muchas de las estrategias e iniciativas de negocios del sector fueron coordinadas bajo la acción colectiva de los dueños de ingenios de la zona. También los completos informes anuales que rinde desde 1987 la Asociación de Cultivadores de Caña de Azúcar, Asocaña, han sido una valiosa fuente de información, siempre acompañada de anexos estadísticos.

\footnotetext{
${ }^{2}$ Con frecuencia en la literatura se considera al Valle del Cauca una región con excepcionales condiciones naturales para el cultivo de la caña. Véase por ejemplo el Informe de la comisión encargada de visitar los ingenios azucareros del pais, 1938, Bogotá, p. 16, en donde los autores se refieren al Valle como una región "única en el mundo” por producir caña todo el año. También la Misión Chardón se refiere a la región en su estudio como una con "condiciones naturales privilegiadas": Chardón (1930, p. 17).

${ }^{3}$ t.m.v.c. : toneladas métricas valor crudo
} 
Sobre fuentes secundarias me referiré brevemente a las que considero son referencia obligada. Uno de los textos que aportó al marco de referencia es el trabajo del historiador Oscar Almario García, sobre La configuración moderna del Valle del Canca, 1850-1940 (Universidad del Cauca, 2013). Este texto destaca la importancia que tuvo la naturaleza de la sociedad valluna en la configuración del tejido empresarial de la región. La del Valle fue una sociedad rural que siguió siendo predominantemente rural por vocación en el siglo xx, cuando ya existían muchos centros urbanos en la región. La importancia del sector agrícola se mantuvo en el siglo Xx, hasta el punto de que la industrialización del campo antecedió a la industria manufacturera, lo que explica en parte la consolidación progresiva de esta agroindustria. (Almario, 2013: 115, 192).

Un referente importante en la historiografía del Valle es la biografía del fundador de La Manuelita, titulada El Fundador. Recuerdos de su vida y acotaciones para la historia económica del Valle del Cauca, (Phanor Eder, 1959), no sólo por lo que concierne a la familia Eder, también por el caudal de información que contiene sobre la evolución socioeconómica de la región en la segunda mitad del siglo XIX y primeras décadas del xx. Escrito y publicado originalmente en inglés en 1913 por el hijo menor del Fundador, esta biografía de casi 600 páginas fue traducida y publicada en Colombia por primera vez en 1959.

De lectura obligada para el interesado en el empresariado azucarero del Valle es el trabajo de José María Rojas, Sociedad y economía en el Valle del Cauca, (1983), en especial la sección titulada "Empresarios y tecnología en la formación del sector azucarero en Colombia, 1860-1980.” Esta colección, publicada por la Universidad del Valle y el Banco Popular hace ya 35 años, destaca el papel que tuvo en el desarrollo agroindustrial de esta región la gestión empresarial y el uso de las nuevas tecnologías, tanto en los cultivos como en la fábrica. Rojas aporta en este texto una tipología original sobre el empresariado regional, y es una fuente importante sobre el período de expansión y consolidación del sector azucarero en Colombia.

De gran interés, por contener un enfoque comparativo interregional, es el texto de Carlos Dávila, Empresariado en Colombia: perspectiva histórica y regional, publicado por la Universidad de los Andes en 2012. En este texto el profesor Dávila hace una caracterización del empresariado colombiano en Antioquia, Bogotá y el Valle del Cauca, y además aporta, un esquema analítico interdisciplinario basado en distintas variables, (como conducta económica, perfil socioeconómico, relación con la política y el Estado, mentalidad y estilo de vida), que resulta de gran utilidad en el análisis del desempeño de los empresarios. Otras nociones teóricas útiles fueron 
las aportadas por el historiador Mario Cerutti en sus trabajos sobre agricultura comercial, por hacer referencia a formas de organización de la producción a escala regional (Cerutti, 2006: 88); nociones como sistema productivo local, o tejido empresarial son útiles para examinar las interdependencias entre el medio rural y el urbano.

Otras lecturas que aportaron herramientas de análisis para el marco teórico fueron aquellas que plantean una serie de variables que se deben considerar al analizar la problemática en las empresas de familia, y las condiciones necesarias para que éstas sobrevivan el paso del tiempo, de generación en generación (John Davis et. al., 1997; Ernesto Poza, 2010; John Ward, 2004); así como el papel de las redes familiares y de parentesco en la existencia de las empresas de familia (Balmori, Voss, Wortman, 1990).

Este trabajo está estructurado en cuatro secciones que señalan las etapas que marcaron un cambio significativo en el desarrollo secular del sector azucarero. Una primera sección se refiere al fundador del ingenio La Manuelita, Santiago Eder Kaiser, y la administración del ingenio de los hijos del fundador, y abarca entre 1861 y 1930. La segunda sección está centrada en la expansión y modernización del Ingenio La Mauelita, lo que ocurre en forma simultánea a la concentración de la producción azucarera en el Valle. La gerencia de Harold Eder Caicedo, (1930-1965), nieto del Fundador, se destaca por la modernización de La Manuelita en los procesos de producción, así como la gestión pública y privada en distintas iniciativas junto con reconocidos líderes de la región. Harold Eder, además, lideró inversiones asociado a otros dueños de ingenios, con el fin de incrementar el volumen de producción regional y aprovechar los insumos de los ingenios en la producción de otros bienes de valor agregado, lo que es tema de la tercera sección del trabajo.

Esta tercera sección también incluye el desempeño de Henry Eder Caicedo, hijo de Harold, quien le sucedió en la dirección de los negocios de la familia, a partir de 1965, siendo los principales logros de su administración la expansión y diversificación del portafolio de negocios de la empresa a otras regiones del país, y su internacionalización con inversiones en distintos países de América Latina.

Una última sección del trabajo aborda los importantes cambios que se dan en la producción del sector azucarero, en la primera década del siglo XXI, como resultado de la diversificación que experimenta el sector en sus portafolios de inversión. Contiene información acerca de la capacidad de generación de empleo del sector, rendimiento comercial, exportaciones y manejo del medio ambiente, en una región en la que la caña al parecer había monopolizado buena parte de los recursos hídricos para la agricultura. 


\section{MAPA 1}

Zonas de cultivo de la caña de azúcar en Colombia

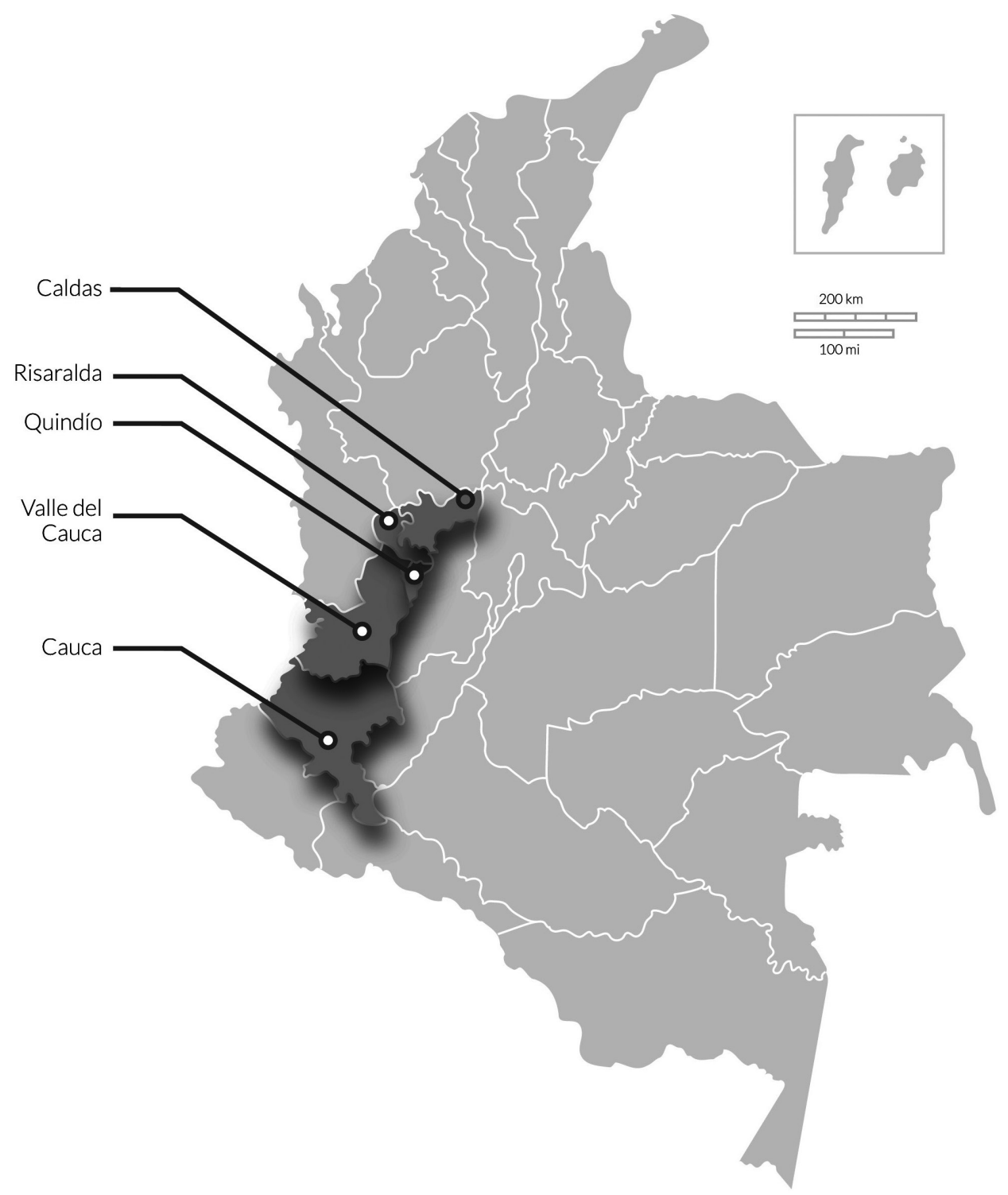

Fuente: Cenicaña. 


\section{MAPA 2}

Ingenios en el Valle del Cauca

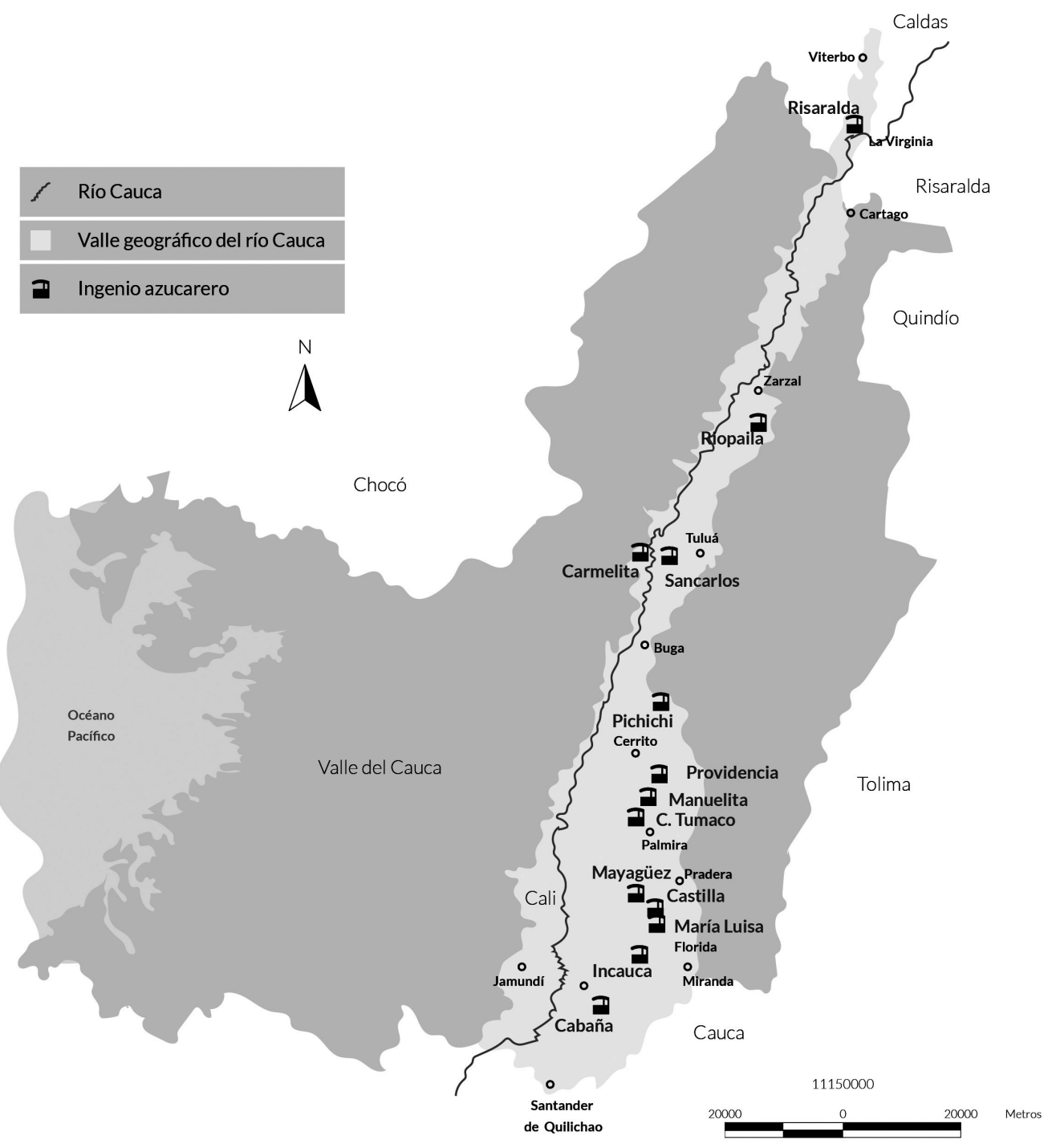

Fuente: Asocaña 


\section{EL FUNDADOR DE LA MANUELITA}

\section{A. Santiago (James) Eder Kaiser, (1838-1921)}

James Eder Kaiser, el fundador de La Manuelita, nació en 1838 en la ciudad de Mitau, en Letonia. ${ }^{4}$ James emigró a Estados Unidos en 1853 después de la muerte de su padre. Tenía 15 años y era el menor de cuatro hermanos que habían emigrado antes, unos a Londres y otros a Nueva York. Los hermanos de James eran hombres de negocios, importadores, comisionistas y contratistas, y tenían intereses económicos en lugares tan distintos como Londres, Guayaquil y países de Centroamérica.

James emigró hacia Estados Unidos siguiendo la ruta trazada antes por su hermano mayor, Henry, quien le esperaba en Nueva York en donde se hizo cargo de su educación. Terminó la secundaria interno en un colegio de esa ciudad, para proseguir su educación en la Academia de Albany, en el estado de Nueva York. En abril de 1858, se matriculó en la Facultad de Derecho de la Universidad de Harvard. En 1859 obtuvo la carta de ciudadanía y unos meses más tarde la licencia para ejercer como abogado en el estado de Massachussets. Ese mismo año se trasladó a California con la intención de ejercer allí su profesión, y aunque también allí obtuvo la licencia para ejercer desistió de sus planes cuando supo que sólo en San Francisco había 268 abogados. Viendo que no tenía muchas opciones de trabajo, emprendió viaje hacia América del Sur, visitando Perú y Chile, en donde permaneció hasta 1861. Salió de Chile ese año y al llegar a Panamá, una filial en esa ciudad de la firma de comercio de la que era socio su hermano mayor lo envió a cobrar unas cuentas en el puerto de Buenaventura.

Fue así como a fines de 1861, a la edad de 23 años, James Eder Kaiser arribó por primera vez a Buenaventura, sin sospechar siquiera que en Colombia transcurriría una parte de su vida. Es probable, aunque no lo dice su biógrafo, que su permanencia en Buenaventura se extendiera más de lo previsto por coincidir con el inicio de la Guerra Civil norteamericana (1861-1865).

${ }^{4}$ La información sobre Santiago y su familia contenida en este apartado procede de la biografía que sobre él escribió en 1913 su hijo menor, Phanor Eder, El Fundador Santiago M. Eder. Recuerdos de su vida y acotaciones para la historia económica del Valle del Cauca (Bogotá: Antares, 1959). Para la época en que Santiago salió de Mitau, en esta ciudad vivía una población predominantemente alemana, sede de los terratenientes de Letonia, aunque el control político había pasado a los rusos (Eder, 1959, p. 13).. 
En Colombia James adoptó el nombre de Santiago, y muy pronto hizo amigos y socios en Buenaventura que le llevaron a conocer el hermoso y fértil Valle del Cauca. En los años siguientes adquirió tierras en la región y combinó sus actividades de hombre de negocios con las de agricultor.

En 1867, a la edad de 29 años, Santiago conoció en un viaje a Londres a Elizabeth (Lizzie) Benjamín, (Londres 1843-Nueva Jersey 1937), con quien se casó cinco semanas más tarde, en junio de 1867. En agosto de ese año ya se encontraban los recién casados en el Valle del Cauca, instalados en la casa de la hacienda La Manuelita, aledaña a la población de Palmira, que ahora era propiedad de Santiago. Allí nacieron sus hijos e hijas.

Los esposos Eder Benjamín vivieron en el Valle del Cauca entre 1867 y 1886, (Eder, 1959, p. 344), un período en el que predominaron en Colombia gobiernos de liberalismo radical, bajo el mandato de una constitución sancionada en 1863, en la Convención de Rionegro. La constitución de Rionegro es conocida por llevar el federalismo a extremos no vistos antes en ninguna otra constitución del hemisferio; esta carta dividió el territorio nacional en nueve estados soberanos casi autónomos, lo que se tradujo en el empoderamiento de las regiones en detrimento del poder ejecutivo, agudizando las confrontaciones regionales y partidistas durante todo el período. ${ }^{5}$

Santiago tenía simpatías por los ideales del liberalismo, debido a su americanismo y a su educación en la tradición liberal, dominante en el siglo XIX (Eder, 1959, p. 346). Pero sus ideales tal vez estaban lejos de ser los que pudo observar en Colombia. Durante las dos décadas de residencia en Palmira, los Eder fueron testigos de varias contiendas civiles y militares en el Estado Soberano del Cauca, con cortos intervalos de paz. Especialmente grave para ellos fue la toma de Cali, el 18 de diciembre de 1876, por los conservadores opuestos al régimen liberal en el poder. El gobierno envió tropas a Cali para restablecer el orden, tropas que durante cinco días asesinaron a muchas personas, saquearon casas, cajas fuertes y almacenes de nacionales y extranjeros sin que los conservadores opusieran resistencia (Eder, 1959, p. 287). Otros disturbios políticos afectaron directamente los intereses económicos de los esposos Eder Benjamín, como ocurrió durante la guerra de 1885, cuando las fuerzas del gobierno entraron a la hacienda La Manuelita en

${ }^{5}$ La Constitución de Rionegro, sancionada en 1863 en esa población antioqueña, es el inicio de un período de activo reformismo conocido como "la república radical" (Bushnell, 1999: 175). 
tres ocasiones, llevándose caballos y a todos los peones, que fueron incorporados al ejército. (Eder, 1959, p. 306).

La inestabilidad política y la violencia partidista desatada en esos años produjeron gran desasosiego en la pareja, y fueron tal vez el motivo por el que decidieron salir del país por un tiempo. Aunque a partir de 1886 Santiago trasladó a su familia a vivir en el exterior, no por ello descuidó sus intereses en el Valle, hacia donde viajaba con alguna frecuencia, permaneciendo allí el tiempo necesario para visitar a sus amistades, inspeccionar sus propiedades y la buena marcha de sus negocios.

Durante los años de su estadía en el Valle, Santiago Eder fue comerciante importador de mercancía y exportador de materias primas, (tabaco, café, quina, caucho y tagua), una actividad común en ese período en que la política económica propiciaba todo aquello que fomentara un crecimiento económico hacia afuera. Uno de los aportes de Santiago a sus colegas comerciantes del Valle fue familiarizarlos con la función de las sociedades anónimas en los negocios, sistema que no había prosperado en la región, retardando su expansión económica. Al mismo tiempo que atendía sus negocios, Santiago adquirió tierras colindantes o vecinas de La Manuelita, en donde hacía ensayos de cultivos, atraído por las condiciones excepcionales de este Valle para la agricultura y la ganadería. Santiago se interesó también en mejorar las precarias condiciones del transporte, colaborando en la construcción de caminos, como Superintendente del camino a Buenaventura, y fue tesorero y promotor activo de la construcción del camino Palmira-Cali. (Eder, 1959, p. 126).

Tampoco descuidó el trapiche que encontró en 1861 cuando adquirió La Manuelita, que con el tiempo evolucionó de ser un trapiche movido por fuerza de sangre, a ser un trapiche que utilizaba energía hidráulica producida por una rueda Pelton, en 1867. En 1873 se instaló el más moderno molino Louisiana 1. Pero la mayor innovación tecnológica que introdujo Santiago en el funcionamiento de la fábrica la inauguró con el cambio del siglo, el 1 de enero de 1901. Se trató de una nueva maquinaria adquirida en Glasgow, necesaria para producir azúcar centrifugada mediante el uso de la fuerza motriz a vapor, siendo el primer ingenio azucarero en el Valle en utilizar esta moderna fuente de energía. Unas 1.200 mulas y 600 bueyes transportaron la nueva maquinaria para la fábrica del ingenio, desde el puerto de Buenaventura hasta Palmira, atravesando la cordillera de los Andes, lo que les tomó más de dos años, debido a la inexistencia de una infraestructura vial. Con las nuevas instalaciones La Manuelita pasó de moler una tonelada de caña al día a moler 50 toneladas. 
El último viaje de Santiago a Colombia fue con Phanor, su hijo menor, en 1903. A principios de 1904 se instaló con su esposa en Nueva York, en el No. 251, West 95 Street, en donde organizó su vida en una rutina que mantuvo hasta el día de su muerte, el 26 de diciembre de 1921. Su esposa Lizzie le sobrevivió 16 años; murió el 24 de junio de 1937, a los 94 años, en su casa campestre en New Jersey (Eder, 1959, pp. 574 y 578).

\section{B. Los Eder Benjamín, primera generación en Colombia}

Santiago y Lizzie tuvieron seis hijos, tres varones y tres mujeres, todos nacidos en Colombia. Lizzie salió definitivamente de Colombia a principios de 1886, hacia Londres, de donde era oriunda, acompañada de sus tres hijos menores: Fanny, Edith y Phanor. Su esposo se le reuniría más tarde.

Los tres hijos mayores: Henry, Charles y Luisa, ya se encontraban en el exterior en donde se educaron. Henry, (1870-1949), estudió en Europa; obtuvo el grado de Ingeniero de Minas en Clausthal, Alemania. Al Valle del Cauca llegó a principios de 1894. Charles, (1872-1942), tomó cursos de contabilidad y manejo de los negocios en el Instituto Comercial Packard de Nueva York, y al graduarse se dirigió al Valle del Cauca. Después de la muerte del padre, en 1921, Charles asumió la dirección y administración de La Manuelita y de las propiedades ganaderas, mientras Henry se dedicó inicialmente a los negocios mercantiles en Cali. Phanor, (1880-1971), el hijo menor, se graduó en 1903 en la Escuela de Leyes de la Universidad de Harvard, y más tarde hizo parte de la firma de abogados Hordin, Hess, Eder and Rashap, en Nueva York, de la que se retiró en 1969.

Los tres varones Eder Benjamín casaron con colombianas, la de Charles hija de un inmigrante italiano. Las tres mujeres Eder Benjamín también formaron familias: Luisa casó con Samuel Jackson Jacobs, con quien vivió en Nueva York. Fanny, (1874-1930), se casó en Londres en 1897 con Henry L. Maduro, un comerciante panameño. Edith, (1878-1942), la hija menor, casó con Carlos Lobo, un ingeniero del Departamento de Acueductos, en 1904.

En 1897, Santiago Eder Kaiser traspasó sus negocios y propiedades a una sociedad anónima que constituyó en Nueva York, la Cauca Valley Agricultural Co. En 1919 esa compañía pasó a llamarse la Compañía Agrícola Caucana, y fue trasladada a Colombia mediante su protocolización en una notaría de Palmira, Valle del Cauca, con el fin de traspasar las propiedades a sus hijos, quedando constituida 
como una sociedad familiar. ${ }^{6}$ Santiago falleció dos años más tarde, como ya se dijo, en su casa de Nueva York, el 26 de diciembre de 1921.

\section{La administración de los hijos del Fundador}

A partir de la protocolización en Colombia de la Compañía Agrícola Caucana, en 1919, los hijos del Fundador van a asumir formalmente la administración de los bienes y de los negocios de la familia. Esta primera generación Eder en Colombia disfrutó de un contexto de mayor estabilidad política y económica, diferente del que experimentaron sus padres, debido en buena medida al auge de las exportaciones cafeteras en las primeras tres décadas del siglo Xx. La producción de café se había multiplicado por seis entre 1905 y 1930, al pasar de 500.000 a tres millones de sacos de 60 kilos. El precio internacional del café se duplicó en la segunda mitad de la década del veinte, lo que generó en la economía colombiana una demanda sostenida de bienes, es decir, la creación de un mercado interno para productos de la agricultura, la ganadería y la incipiente industria manufacturera. ${ }^{7}$ Además, entre 1923 y 1928 entraron al país 200 millones de dólares en forma de créditos, y el pago gradual de 25 millones de dólares de la indemnización por la intervención norteamericana en la separación de Panamá. (Urrutia, 2017, p. 84).

Estos recursos se destinaron en su mayoría a la construcción de obras públicas, en particular infraestructura de transporte. Entre 1924 y 1929 se construyeron más de 1.000 kilómetros de líneas férreas y cerca de 1.800 kms. de carreteras, (Ramirez, 2015, pp. 161-62), mejoras necesarias para el avance del desarrollo económico.

Charles Eder Benjamín asumió formalmente la Gerencia de la empresa familiar después de la muerte de su padre. Durante su administración (1921-1928) se hicieron algunas mejoras en la fábrica de La Manuelita en 1927, bajo la asesoría de He Honolulu Iron Works Co., una compañía de ingenieros consultores y contratistas de Hawái con filial en Nueva York, a la que seguiría vinculada la empresa

${ }^{6}$ La Cauca Valley Agricultural Co. fue protocolizada en Palmira el 17 de agosto de 1919, Notaría 1, Escritura No. 421. Constituida en sociedad familiar como Compañía Agrícola Caucana, según Escritura 378 del 23 de julio de 1919, Not. 1, Palmira.

${ }^{7}$ Sobre el periodo 1905-1930, véase Caballero (2015). "El proceso económico”, en Posada, E. y Deas, M. (director y coordinador) (2015), Colombia. Mirando hacia dentro, América Latina en la Historia contemporánea, Tomo 4, Mapfre, Taurus, Penguin Random House, España, pp. 149-150. 
en las siguientes décadas. (Eder, 1959, p. 581). Como resultado de estas mejoras la capacidad de molienda de la Manuelita se incrementó de 200 a 500 toneladas de caña en 24 horas, y la capacidad de producción en 1927 pasó a ser de 3.750 toneladas métricas de azúcar al año. En ese entonces la fábrica molía sólo 12 horas al día y no las 24 horas que eran indispensables para generar economías de escala y reducir los costos de producción (Eder, 1959, p. 582).

En 1928 Charles Eder Benjamín renunció a la Gerencia de Manuelita, y vendió dos terceras partes de sus acciones en la compañía familiar a sus hermanos Henry y Phanor, y a su consuegro Jorge Garcés. ${ }^{8}$ Fue elegido para sucederlo el norteamericano Edwin L. Anderson, un tecnólogo azucarero de larga experiencia en Cuba (Eder, 1959, pp. 582-83). Una característica de la Gerencia de Charles había sido la contratación frecuente de extranjeros para distintos cargos en La Manuelita, a quienes se pagaban altos salarios en dólares o en libras esterlinas. Fue uno de los motivos por los que su gestión fue duramente cuestionada por su hermano Henry, quien se quejaba de que los altos salarios pagados no correspondían al desempeño de estos empleados extranjeros, que en su opinión había sido desastroso para la empresa, como se podía ver en la contabilidad y en el laxo horario de trabajo que tenían. Las cuentas que presentaban el Administrador y el Contador generalmente estaban erradas por falta de controles, y en palabras de Henry (...) todo andaba en desorden, y el despilfarro y el robo estaban a la orden del día (AHLM, Acta 18 de Asamblea General de Accionistas, 1937, Caja 4 Carpeta 22).

La situación había sido denunciada por Harold Eder Caicedo, (1903-1965), hijo de Henry, y su suplente en la Junta Directiva. En 1929, como Revisor Fiscal encargado, Harold llevó a cabo una exhaustiva inspección de los libros de la Sociedad que demostró los descuidos y errores de quien fuera el Contador de la empresa. El informe negativo que rindió Harold como Fiscal (e) tuvo como consecuencia la renuncia del Gerente E. Anderson, (AHLm, Caja 4 Carpeta 8, Acta No. 11 de 26 mayo 1930, N.Y.), lo que daría un giro importante a la administración de la empresa que marcó el inicio de una nueva etapa. En la Asamblea General de Accionistas del 27 de octubre de 1930 se procedió a elegir por votación a quien ocuparía la vacante en la Gerencia que dejó Anderson, resultando elegido por unanimidad Harold Eder Caicedo, quien tenía entonces 27 años (AHLM, Acta No. 9, 1930, Caja 4 Carpeta 17).

\footnotetext{
${ }^{8}$ Mary Eder Cerruti, hija de Charles, casó con Armando Garcés, hijo de Jorge.
} 
Con la elección de Harold Eder Caicedo en la Gerencia de La Manuelita se inicia el traspaso gradual del manejo administrativo y agrícola de la empresa familiar a la segunda generación Eder en Colombia, lo que sería decisivo en su crecimiento y consolidación en los años siguientes. Los hijos del Fundador eran en ese momento (1930) los principales accionistas de la compañía.

Para el mes de febrero de 1931 habían ocurrido tres cambios importantes en la compañía: uno, se dejó de emitir acciones preferidas (de número limitado y por valor de cien pesos cada una) y todas las acciones pasaron a ser ordinarias, es decir, con el mismo valor de diez pesos por acción. Dos, el capital social se incrementó de 2.000.000 de pesos oro legal, a 2.400.000 pesos oro legal, mediante la emisión de 240.000 acciones ordinarias de 10 pesos cada una; y tres, Manuelita fue objeto de una reorganización administrativa (AHLM, Actas de 1928 a 1931: Caja 1 carpeta 13).

\section{CRECIMIENTO Y MODERNIZACIÓN DE LA MANUELITA, 1930-1965}

Harold Eder Caicedo estuvo al frente de la empresa de familia durante más de 30 años, primero en la Gerencia, y más adelante en la Presidencia, en un período de cambios importantes para la empresa y para el sector. Bajo su administración se produjeron la expansión y modernización de la producción, en la fábrica y en los cultivos de caña de azúcar, mediante la innovación en tecnologías, en los procesos de producción y en los productos. Fue un período de crecimiento regional del sector, con base a avances tecnológicos aplicados en el manejo agrícola y fabril, sumado al incremento del número de fábricas en el Valle. Este incremento en la producción coincidió con el cierre de ingenios en otras regiones productoras del país al promediar el siglo xx, lo que consolidó el dominio de los azucareros del Valle sobre el mercado interno al finalizar la década de los años cincuenta.

El nuevo Gerente, Harold Eder Caicedo, era el único hijo varón de Henry Eder Benjamín y Benilda Caicedo Lozano. Tenía tres hermanas: Elisa, Luisa y Amy. Al igual que su padre, sus tíos y su hijo, Harold tenía una sólida formación profesional, lo que en la Colombia de 1930 representaba el privilegio de muy pocas personas. ${ }^{9}$ Estudió desde los 12 años en Choate School, un colegio para varones

\footnotetext{
${ }^{9}$ De los más de seis millones de habitantes que había en Colombia en 1920, alrededor del 80 por ciento vivía en el campo, concentrados en la región Andina. La mayoría de los habitantes seguía afectada por los mismos
} 
en Wallingford, Connecticut. ${ }^{10}$ Se graduó en Ingeniería Eléctrica, en el Massachusetts Institute of Technology. A su regreso a Colombia contrajo matrimonio con su prima, Cecilia Caicedo Méndez, con quien tuvo tres hijos, Doris (1933), Elisa (1930) y Henry (1935) (Castro, 2010, p. 15). Sus aportes a la empresa familiar, a la región y especialmente al sector azucarero del Valle, fueron decisivos en la consolidación del sector y en el liderazgo de la producción nacional, como se verá a continuación.

\section{A. Los laboratorios experimentales, la electrificación regional y la agremiación del sector}

La administración de Harold Eder se inició en 1930, un momento difícil por la crisis mundial que afectó los precios de las materias primas, pero positivo desde la perspectiva del desarrollo agroindustrial del Valle del Cauca. Este desarrollo se benefició especialmente de dos factores. El primero fueron los avances que lograron los ingenios en las décadas de 1930 y 1940, en el manejo agrícola de los cañaverales, con el apoyo de científicos, tanto en los cultivos de caña como en los procesos de producción de azúcar. En esto los productores del Valle fueron innovadores, puesto que en general en las zonas azucareras de fines del XIX y principios del siglo XX, tanto en Colombia como en América Latina, la inversión se concentró en la producción fabril, y no tanto en el cañaveral, subestimando el manejo de la vertiente agrícola del negocio (Tortolero V., 1995, p. 304). El segundo factor de desarrollo regional, igualmente importante, fue la creación de la Corporación Autónoma Regional del Valle del Cauca, en 1954, por el impacto transformador que ésta tuvo en el desarrollo económico regional.

Reconocidos líderes del sector agrícola y pecuario del Valle del Cauca se encargaron de llevar a cabo la gestión pública y privada necesaria para hacer realidad esta transformación agrícola y tecnológica. El estudio de la trayectoria de Ciro Molina Garcés (1891-1953) y de su contemporáneo Carlos Durán Castro (1897-1993) son un buen testimonio de ello. La gestión pública de Ciro Molina

problemas del pasado: altas tasas de analfabetismo que rondaban el 70 por ciento, pobreza extrema y exclusión de la vida política (Arias, 2011).

${ }^{10}$ El Choate School de Wallingford, en Connecticut, era al parecer un colegio privado prestigioso, en el que también se educó su hijo Henry: AHLM, Caja 3 carpeta 2, en carta de Harold al Rector del citado colegio en 1951. 
y Carlos Durán fue de gran eficacia desde la Secretaría de Industrias del Departamento, entre 1926 y 1930, al poner en marcha la modernización del agro regional (Mejía P., 2002, pp. 1197-98).

Una de las tareas encomendadas a Carlos Durán Castro en la Secretaría de Industrias fue la contratación de una misión científica para la realización del primer estudio agronómico del Valle del Cauca. Durán Castro conocía el trabajo del agrónomo puertorriqueño Carlos Chardón, quien fuera invitado en 1926 por la Sociedad Agrícola de Antioquia para reorganizar la Escuela Superior de Agricultura de Medellín. ${ }^{11}$ El trabajo de Chardón en Antioquia atrajo la atención del gobierno del Valle del Cauca, y en 1928 fue invitado a conducir una investigación sobre las condiciones agrícolas y pecuarias del departamento, y a elaborar un plan para el montaje de una estación agrícola experimental. Resultado de la Misión Chardón fue el detallado informe de 342 páginas que recoge sus observaciones y recomendaciones, ${ }^{12}$ empresa en la que contó con el apoyo gubernamental, el de los cultivadores y el de los dueños de ingenios. Poco tiempo después de terminada la Misión el gobierno estableció una estación agrícola experimental en una finca de 240 hectáreas en Palmira (McCook, 2001, p. 68).

Uno de los aportes importantes de la Misión Chardón en el Valle fue la importación de 15 variedades de caña que se sembraron en la Estación Experimental de Palmira. (Chardon, 1930, p. 161). En 1930, según Chardón, la casi única variedad de caña sembrada en el Valle era la llamada caña blanca u Tahití, que ya había sido reemplazada en la mayoría de los países productores por variedades más eficientes. (Chardon, 1930, p. 9). Dos de esas variedades, la POJ 2775 y la POJ 2778, arrojaron excelentes resultados en materia de productividad y rendimiento. Esto era una innovación importante, pues hasta entonces los determinantes en el volumen de producción de azúcar eran el tamaño del área del cultivo y el régimen de lluvias, y no la concentración de sacarosa en la caña (McCook, 2001, p. 56).

Entre 1950 y 1960, en forma paralela y con el apoyo del Estado, surgieron un conjunto de instituciones que fueron estratégicas para el desarrollo regional y el avance del sector. Una de las más importantes fue la creación de la Corporación

${ }^{11}$ Carlos Chardón alcanzó mucho prestigio por ser quien descubrió el origen de la plaga del mosaico en los cañaverales. Había hecho un doctorado en la Universidad de Cornell entre 1919 y 1927. Véase McCook (2001).

${ }^{12}$ Chardón (1930). La Misión Chardón estaba conformada por cinco científicos puertorriqueños: uno era Veterinario y Zootecnista de la U. de Pennsylvania; otro era Patólogo Vegetal, de la U. de Cornell; un tercero era Agrónomo de Cornell; y el cuarto era el Secretario (datos tomados del Informe Chardón). 
Autónoma Regional del Valle del Cauca, en 1954, por los efectos transformadores que tuvo en el posterior desarrollo económico regional, basado en la explotación de tres elementos principales, tierra, agua y energía. ${ }^{13}$

La idea de crear un organismo especial para el manejo de los recursos naturales de la región venía desde los años veinte. Hubo varias iniciativas previas en esa dirección: en 1945, el Secretario de Agricultura Ciro Molina contrató con una firma de Nueva York un estudio sobre los recursos hidrográficos de la región. En 1949, el gobierno departamental contrató a la firma de ingenieros Olarte, Ospina, Arias y Payán, OLAP, de Bogotá, para estudiar el potencial regional en la generación de energía eléctrica e irrigación. En la elaboración de ese informe, titulado Plan para el desarrollo económico de la cuenca hidrográfica del Alto Cauca, se sugería la creación de una corporación de desarrollo regional, con la idea de explotar la rica cuenca hidrográfica del Valle e indagar sobre su potencial para la generación de energía (Jackson, 1972, pp. 95-96).

Finalmente, la gestión del Gobernador del Valle, a través del Embajador de Colombia en Washington, produjo la visita de David Lilienthal al país, en 1954, quien después de varios meses de estudios recomendó al gobierno central escoger a la región del Valle del Cauca para el programa de desarrollo regional de recursos naturales. Las razones que argumentaba eran físicas, técnicas y económicas, pero sobre todo Lilienthal subrayaba la importancia del capital humano que había detectado en el Valle, al referirse a la existencia de un grupo de líderes locales en la región, con iniciativa y altamente motivado e interesado en apoyar el programa (Jackson, 1972, p. 90).

Fue así como mediante el Decreto Ley No. 3110, emitido cuatro meses después de presentado el Informe Lilienthal, surgió la Corporación Autónoma Regional del Valle del Cauca, “(...) como un establecimiento público, con personería jurídica, autonomía administrativa y patrimonio propio, destinada a cumplir en una zona dada varios servicios que antes estaban adscritos al Estado" ${ }^{14}$ Para la Junta Directiva de la Corporación se escogió al comité de planificadores de la Gobernación del Valle, conformado por el grupo de líderes a los que había hecho referencia

\footnotetext{
${ }^{13}$ Sobre la Corporacion Autónoma del Valle del Cauca, véanse Posada y Posada (1966) y Jackson (1972).

${ }^{14}$ La C.V.C. se creó mediante el Decreto Legislativo No. 3110, de 22 de octubre de 1954, porque el Congreso había sido clausurado desde 1949 por el Presidente Mariano Ospina Pérez. Este Decreto quedó sin valor jurídico en 1957, y obtuvo de nuevo apoyo político del Congreso.
} 
Lilienthal. Fue así como la Junta Directiva de la nueva Corporación Regional quedó conformada por: el Gobernador, Diego García Giraldo, propietario de bienes raíces urbanos y rurales; Manuel Carvajal Sinisterra, empresario; Harold Eder Caicedo; José Castro Borrero, empresario y líder cívico; Luis Sanclemente Crespo, entonces Secretario de Vivienda del departamento. Bernardo Garcés Córdoba, con intereses en el sector agropecuario, fue nombrado director ejecutivo de la nueva organización (El País, Cali, noviembre 13, 1954). Este grupo creó los estatutos de la Corporación.

El patrimonio de la C.V.C. y su financiación, según A. J. Posada, provino de contribuciones directas e indirectas del gobierno nacional y departamental. La financiación básica, según Posada, tuvo su origen en un impuesto predial adicional del cuatro por mil cobrado en el Valle a predios cuyos propietarios tuvieran un patrimonio líquido superior a 50.000 pesos. Y en 1966, a un gravamen del tres por mil a los poseedores de bienes raíces con un patrimonio mayor a los 100.000 pesos (Posada, 1966, p. 68).

G. Jackson en el citado estudio subraya la importancia que tuvieron los préstamos de organismos internacionales y de gobiernos extranjeros en la financiación de las obras de la C.V.c. Para este investigador, el aporte financiero más importante de instituciones internacionales estuvo dirigido a los proyectos de electrificación y en menor grado a los de agricultura. ${ }^{15}$

La C.V.C. aportó, en la década de 1960, grandes transformaciones en la región, entre las cuales se destacaron las hidroeléctricas en el Valle y en el Cauca para la electrificación de buena parte de la región cultivada en caña; y la adecuación del río Cauca, mediante la construcción del embalse de Salvajina (Cauca), y obras complementarias, que permitieron recuperar más de 80.000 hectáreas de terrenos para el cultivo de la caña, antes inundables por las crecientes del río Cauca y sus afluentes (Posada, 1966; Millán, 2002).

Por último, una iniciativa importante a favor del desarrollo regional fue la agremiación de los productores de azúcar del Valle bajo la Asociación de Productores de Caña de Azúcar, ASOCAÑA, en febrero de 1959, como una organización

${ }^{15}$ Por ejemplo, el proyecto hidroeléctrico de Calima fue financiado por el Banco Mundial. Entre 1954 y 1971, el BM prestó a la CVC más de us $\$ 28$ millones (Jackson, 1972, pp. 69-71). El proyecto hidroeléctrico del Alto de Anchicayá fue financiado por el Banco Interamericano de Desarrollo que, también entre 1961 y 1971, prestó a la CVC más de us $\$ 20$ millones. Por su parte, el proyecto de electrificación rural recibió un gran apoyo de USAID (Jackson, 1972). 
privada, sin ánimo de lucro, vocera de los intereses de los ingenios y de los cultivadores de caña. Asocaña surgió en momentos en que los azucareros veían con gran interés la inserción en el mercado internacional, estimulados por el incremento en la producción. Esta aspiración hacía necesario unir esfuerzos para lograr una mejor interlocución con las instituciones gubernamentales, tema sobre el que volveré más adelante.

\section{B. La producción azucarera en Colombia en la década de 1930}

En 1928, existían 16 ingenios en Colombia, distribuidos en cinco departamentos así: siete en el Valle del Cauca, cinco en Cundinamarca, dos en Bolívar, y en Chocó y Santander uno en cada uno. El Valle era la principal región productora, por el número de ingenios y porque sus condiciones naturales le permitían una producción continua durante los 365 días del año.

El Cuadro 1 muestra la distribución regional de la producción de azúcar ente 1932 y 1938. Colombia produjo en siete años (1932-1938) un total de 4.821 .828 quintales de azúcar, (equivalente a 482.182,8 toneladas métricas), de la cual un poco más de la mitad, 57,57 por ciento, provino del Valle del Cauca, y una tercera parte, 34,10 por ciento, de la región Caribe. Entre la región Caribe y el Valle produjeron el 91,67 por ciento del total del azúcar en ese período.

Los ingenios colombianos habían logrado sobrellevar el desplome de los precios del azúcar causado por la crisis de 1930, inicialmente con el apoyo del gobierno, a través de la Seccional de Crédito Azucarero, y a partir de 1938 con la creación de la Compañía Distribuidora de Azúcares, una sociedad comercial anónima en la que suscribieron acciones los siete principales ingenios del país. ${ }^{16} \mathrm{La}$ Distribuidora se encargó de mantener la equitativa distribución y venta del azúcar en el mercado nacional a través de sus 32 agencias, distribuidas en el territorio nacional, contribuyendo así a la estabilización del precio y a evitar una competencia desleal. La Seccional y la Distribuidora serían las primeras entidades en la que los ingenios trabajarían asociados.

${ }^{16}$ Los accionistas de la Distribuidora de Azúcares eran los ingenios Manuelita, Central Colombia (Sincerín), (con 1.250 acciones cada uno); Providencia, (650 acciones); Berástegui, (500 acciones); Riopaila, (400 acciones); San Antonio, (300 acciones); y Bengala, (150 acciones). (Ripoll, 2007, p. 66). 
CUADRO 1

El titulo debe ser Colombia: Producción de azúcar por regiones, 1932-1938 (en quintales)

\begin{tabular}{|c|c|c|c|c|c|}
\hline Años & Valle & Región Caribe & Cundinamarca & Santander & Totales \\
\hline 1932 & 281.004 & 228.094 & 38.388 & 4.000 & 551.486 \\
\hline 1933 & 367.343 & 179.746 & 36.117 & 5.000 & 588.206 \\
\hline 1934 & 381.953 & 244.521 & 57.075 & 5.000 & 688.549 \\
\hline 1935 & 358.093 & 220.511 & 59.348 & 6.000 & 643.952 \\
\hline 1936 & 354.760 & 208.937 & 45.000 & 6.000 & 614.697 \\
\hline 1937 & 440.556 & 290.962 & 53.407 & 6.000 & 790.925 \\
\hline 1938 & 592.000 & 271.613 & 74.400 & 6.000 & 944.013 \\
\hline Totales & 2.775 .709 & 1.644 .384 & 363.735 & 38.000 & 4.821 .828 \\
\hline$\%$ & $57,57 \%$ & $34,10 \%$ & $7,55 \%$ & $0,78 \%$ & $100 \%$ \\
\hline
\end{tabular}

Un quintal equivale a 100 kilos; 1000 kilos = una tonelada métrica.

Fuente: Informe de la comisión encargada de visitar los ingenios azucareros del país. (1938), p. 72. Cenicaña, Cali.

En la década 1930-1940, La Manuelita centró la atención en mejorar el manejo agrícola del proceso de producción en los cañaverales, y posteriormente en la fábrica. (AHLM, Caja 4 carpeta 15). Esta estrategia se basó en la expansión de los cultivos de caña, adquiriendo nuevas tierras en la colindancia de La Manuelita, (Cuadro 2), y mejorando el rendimiento de las cañas.

Eder mejoró el rendimiento del cañaveral al resembrar 257,9 fanegadas de cañas, reemplazando las cañas viejas que habían cumplido su ciclo de mayor producción, y sembrando seis variedades nuevas, con el fin de poder seleccionar las más adaptables y de mayor rendimiento. Esto implicaba la presencia de un ingeniero agrónomo permanente para el acopio continuo de datos que le permitiera hacer comparaciones. Otras mejoras importantes, relacionadas con los cultivos, fueron la construcción de seis pozos artesianos para el riego, mejoras en la recolección y transporte de la caña a la fábrica en el ferrocarril, y la construcción de nuevos campamentos para trabajadores. (AHLM, Informe del Gerente, 1931, Caja 4, Carpeta 15). 


\section{CUADRO 2}

Tierras adquiridas por La Manuelita bajo

la administración de Harold Eder,

$1930-1944^{17}$

\begin{tabular}{|l|c|c|c|}
\hline \multicolumn{1}{|c|}{ Tierras } & $\begin{array}{c}\text { Extensión } \\
\text { (fanegadas) }\end{array}$ & $\begin{array}{c}\text { Extensión } \\
\text { (en hectáreas) }\end{array}$ & $\begin{array}{c}\text { Valor } \\
\text { (pesos oro legal) }\end{array}$ \\
\hline Hacienda Real & 446 & 285,44 & 44.605 \\
\hline Hda. San Rafael & 96 & 61,4 & 20.000 \\
\hline Albión & 449 & 287,36 & \\
\hline El Placer & 278 & 177,9 & \\
\hline El Olimpo & 125 & 80 & \\
\hline La Cabaña & & & \\
\hline La Carbonera & 512 & & \\
\hline El Hato & & & \\
\hline
\end{tabular}

Fuente: AHLM, Caja 5, Carpetas 15, 17. Phanor 1959: 583, 584.

La evaluación de los primeros diez años de la administración de Harold Eder es visible en el extenso informe que rindió a la Junta Directiva en 1940.18 En este informe Eder muestra con cifras el mayor rendimiento de las nuevas variedades sembradas, como la P.O.J. 28-78. Los resultados están a la vista en la comparación de indicadores del Cuadro 3, al que se añadieron los datos de La Manuelita, que aparecen en el Informe de 1940.

En el Cuadro 3 vemos que la producción de la variedad de caña P.O.J. 28-78 fue superior a la de la caña criolla (blanca u otahiti) en 78,14 toneladas de caña por plaza. En rendimiento azucarero, la P.O.J. también aventajó a la caña criolla en 8.87 toneladas de azúcar por plaza. Este resultado contrasta aún más con el

\footnotetext{
${ }^{17}$ Antes de que Harold Eder iniciara esta compra de tierras se habían adquirido algunas haciendas colindantes con las del Ingenio La Manuelita, (haciendas El Cambio, El Rosario, en 1924, y en 1926 Santa Gertrudis). (Phanor 1959: 583, 584). El Informe citado dice que Harold Eder pagó por Hacienda Real \$ 44.605,25 pesos, de los cuales \$ 21.672 fueron en efectivo y el saldo en créditos hipotecarios a favor del Banco Agrícola Hipotecario. (AHLM, Caja 4, Carpeta 15, 1932)

18 “AhLm, “Año de 1949”, Caja 1, Carpeta 18. Una síntesis de este informe en la Caja 4 Carpeta 15.
} 


\section{CUADRO 3}

Estudio de variedades de caña de azúcar

Estación Experimental de Palmira, 1938,

$t=$ tonelada; $p l=$ plaza

\begin{tabular}{|l|c|c|c|c|c|}
\hline \multicolumn{1}{|c|}{ Variedad } & ${ }^{\circ}$ Brix $^{*}$ & Sacarosa & Pureza & $\begin{array}{c}\text { Rendimiento } \\
\text { t.caña/pl. }\end{array}$ & $\begin{array}{c}\text { Rendimiento } \\
\text { t. azúcar/pl. }\end{array}$ \\
\hline P.O.J. 28-78 & 18,75 & 16,33 & 87,07 & 113,36 & 11,959 \\
\hline B.H. 10-12 & 19,55 & 17,65 & 90,24 & 49,5 & 5,723 \\
\hline Criolla & 16,65 & 13,92 & 83,43 & 35,22 & 3,082 \\
\hline $\begin{array}{c}\text { P.O.J. 28-78 en } \\
\text { La Manuelita }\end{array}$ & - & 11,27 & 79,49 & 142,74 & 13,7 \\
\hline
\end{tabular}

Hemos añadido la información sobre La Manuelita. La caña de La Manuelita tenía 17 meses, era el primer corte, y arrojó un rendimiento de 9,6 \%. (AHLM, Caja 1, carpeta 18, Informe año 1940).

* ${ }^{\circ}$ Brix: Los grados Brix son una unidad de cantidad que sirve para determinar el cociente total de materia seca (generalmente azúcares) disuelta en un líquido. Los ${ }^{\circ} \mathrm{Bx}$ se cuantifican con un refractómetro.

Fuente: Informe de la comisión encargada de visitar los ingenios azucareros del país. (1938). Bogotá, p. 22. Una plaza $(\mathrm{pl})=$. una fanegada $=0,64$ hectáreas.

rendimiento de la P.O.J. en La Manuelita, que en el primer corte de caña de 17 meses, aventajó a la criolla en 10.62 toneladas de azúcar por plaza. En algunos ingenios las P.O.J. llegó a producir un rendimiento hasta en el séptimo corte consecutivo, y aún en el séptimo corte el rendimiento fue mayor que el de la caña criolla.

Una enumeración de los artefactos usados en la fábrica en el proceso de producción de azúcar (AHLM, Caja 12 carpeta 22) nos indica que el Ingenio tenía lo requerido en 1940 para producir azúcar centrifugada. No había ningún ingenio que produjera azúcar refinada en ese momento. Manuelita producía también alcohol y mieles. En 1940 la miel o melaza era vendida para los alambiques de la zona, y también como alimento para cebar ganado; más adelante las mieles serán exportadas.

El Balance General de La Manuelita, a diciembre 31 de 1940, arrojó una utilidad neta de \$1.334.951,31. 


\section{Panela vs. azúcar}

Una de las pocas confrontaciones que debió afrontar Eder con la comunidad ocurrió en la década de los años cuarenta, cuando tuvo la idea de producir panela en forma eficiente. La fabricación de panela en Colombia ha sido una actividad muy extendida desde tiempos coloniales. Suele ser una industria de carácter rural y campesino, pues son por lo general las zonas rurales y los pueblos los principales consumidores de panela.

En 1942 la industria panelera en Colombia contaba con 37.000 establecimientos extendidos por todo el país, y producía cerca de ocho millones de quintales de panela al año, (800.000 toneladas), una producción mucho más alta que la del azúcar, que para ese entonces estaba cerca de 1.200 .000 quintales (120.000 toneladas) (Caicedo, 1965, p. 261). Los precios del azúcar, por lo general más altos que los de la panela, mantenían el consumo panelero más o menos estable, salvo en las pocas ocasiones en las que por alguna coyuntura pasajera el precio del azúcar bajaba al nivel de la panela. El azúcar a bajo precio, estaba comprobado, desalojaba la panela de su mercado habitual.

La Manuelita, atraída tal vez por esta anomalía, decidió montar una empresa panelera y lo hizo en su hacienda La Cabaña, con una producción que por varios años entró a competir en el mercado panelero. En 1940, por ejemplo, produjo 85.338 arrobas de panela, de las cuales vendió $83.246 @$ por un valor de $\$ 107.121,60$ en bultos y cajas. (AHLM, Caja 4, Carpeta 15). Esta competencia, que además venía del Ingenio más grande del país, ocasionó mucho malestar en el gremio de paneleros por considerar que afectaba directamente a la población más vulnerable, la del campesinado, su principal productor y consumidor. Se decía que el fin de La Cabaña no era otro que el de envilecer el precio de la panela para facilitar a La Manuelita la absorción de las fincas paneleras vecinas. La protesta llegó hasta el punto que el gobierno central tomó cartas en el asunto y el Presidente Eduardo Santos clausuró el negocio de panela en La Cabaña.

La Manuelita, no contenta con la acción gubernamental, mudó la fábrica panelera de Palmira (Valle) a Armero (Tolima), en donde la producción resucitó bajo una nueva razón social en la finca El Triunfo, en la que Harold Eder se asoció con la señora María Sierra de Gómez. Y por si ello fuera poco, montó una segunda fábrica en Palmira, en la hacienda San José, en la que La Manuelita aportó el 50 por ciento del capital. Esta vez la protesta de los paneleros del Valle se extendió a todo el país, y el Congreso de la República, la Sociedad Colombiana de Agricultores, 
la Cámara de Comercio y la prensa colombiana convirtieron el asunto en un problema nacional que llevó finalmente a La Manuelita a darle un uso diferente a sus haciendas paneleras. ${ }^{19}$

Otras inversiones de La Manuelita en la década de 1940 fueron hechas en sus haciendas filiales y en otras industrias colombianas, como se puede ver en el listado de acciones anotado en diciembre de 1947, reproducido en el Cuadro 4.

Durante la década de 1940 el número de ingenios en el Valle aumentó progresivamente; al final de la década de 1950, de los 22 ingenios que había en el país, 18 estaban en el Valle, seis de ellos en el municipio de Palmira. El Cuadro 5 nos muestra el aumento progresivo en la producción del Valle a lo largo de esa década, hasta llegar a representar, en 1950, el 80,5 por ciento del total de la producción colombiana de azúcar. Y no bajaría en las décadas siguientes.

\section{CUADRO 4}

Acciones de La Manuelita en filiales y en otras industrias, 1947

\begin{tabular}{|l|c|c|}
\hline \multicolumn{1}{|c|}{ Filiales e industrias } & Número de acciones & Valor en libros \\
\hline La Carbonera & 32.526 & 325.260 \\
\hline Cementos del Valle & 293.832 & $792.179,22$ \\
\hline Ingenio Providencia & 33.000 & 625.500 \\
\hline Cementos Diamante & 12.705 & $172.112,39$ \\
\hline Compañía Col. de Tabaco & 23.760 & 247.641 \\
\hline Cervecería Bavaria & 184.981 & $521.340,72$ \\
\hline Distribuidora de Azúcares & 2.290 & 22.900 \\
\hline Editorial La Razón & 50 & 1.00 \\
\hline Ing. Central del Tolima & 177.146 & 1.790 .721 \\
\hline La Cabaña & 41.000 & 533.000 \\
\hline La Hacienda Real & 45.000 & 463.440 \\
\hline La Paz S.A. & 3.260 & 326.000 \\
\hline Petróleos Ariguaní & 859 & $1.737,08$ \\
\hline Providencia S.A. & 3.260 & 326 \\
\hline
\end{tabular}

Fuente: AHLM, Caja 4 Carpeta 57.

\footnotetext{
${ }^{19}$ Sobre el tema del azúcar vs. la panela, ver Caicedo, 1965, quien le dedica varios capítulos al tema. Caicedo era dueño del Ingenio Riopaila.
} 


\section{CUADRO 5 \\ Producción de azúcar en Colombia y en el Valle del Cauca, 1941-1950 \\ (quintales)}

\begin{tabular}{|c|c|c|}
\hline Año & En Colombia & En el Valle \\
\hline 1941 & 1.160 .544 & 801.713 \\
\hline 1942 & 1.270 .262 & 828.040 \\
\hline 1943 & 1.346 .528 & 950.454 \\
\hline 1944 & 1.443 .982 & 975.917 \\
\hline 1945 & 1.527 .521 & 1.165 .900 \\
\hline 1946 & 1.529 .126 & 1.101 .493 \\
\hline 1947 & 1.664 .845 & 1.194 .596 \\
\hline 1948 & 2.171 .602 & 1.631 .468 \\
\hline 1949 & 2.769 .011 & 2.244 .862 \\
\hline 1950 & 2.928 .947 & 2.358 .091 \\
\hline
\end{tabular}

Fuente: Eder, 1959, p. 590, y cifras de la Distribuidora de Azúcar.

La producción de azúcar centrifugada, entre 1940 y 1974, aumentó 18,5 veces, al pasar de 48.089 toneladas a 894.820 toneladas, resultado del aumento del número de ingenios en el Valle del Cauca.

Según la opinión de un contemporáneo, el éxito de la industria azucarera en el Valle se debía, en primer lugar, a que la industria se pudo desarrollar con costos de producción moderados, gracias a las excepcionales condiciones naturales de la zona; y en segundo lugar, a las características de las empresas que la explotaban. Sobre lo segundo dijo:

A ese respecto hay que poner de relieve el hecho de que allí el empresario es, o una sociedad compuesta de miembros de una misma familia, o de hombres muy relacionados entre sí. De este modo el empresario es a la vez capitalista y director del negocio, y si lo considera como fuente de ganancias es evidente que halla en su creación, mantenimiento y ensanche, un buen lote de alegría y satisfacción, fuerzas estas que lo impelen a seguir adelante y que sería inútil buscar en el accionista disperso de las grandes sociedades anónimas. (...) (Eder, 1959, p. 590). 
Las observaciones de este contemporáneo sobre la ventaja de las empresas del Valle muestran una vez más el papel de las redes familiares en las que están inmersas estas empresas azucareras. Los dueños de ingenios del Valle, con un mismo perfil socioeconómico, suelen mantener sus transacciones de negocios con quienes les generan confianza, y las relaciones de parentesco y de amistad resultan claves en ese contexto. (Dávila, 2012, pp. 64-65).

\section{Innovación en el producto y en el proceso de producción, 1950-1965}

Además de avanzar en la expansión de los cultivos de caña y en la siembra de variedades de mayor producción y rendimiento, durante la administración de Harold Eder La Manuelita amplió en dos ocasiones su capacidad de producción. Su propósito era aumentar la acumulación de excedentes para exportar, y al mismo tiempo ser cada vez más competitivo en el mercado interno ofreciendo azúcar refinada. La Manuelita fue el primer ingenio del Valle en ofrecer azúcar refinada en el mercado colombiano.

La maquinaria necesaria para la ampliación y modernización de la producción fue negociada con la firma Hawaian Iron Works Co., (en adelante H.I.w.), sus antiguos proveedores (AHLM, Acta 27, 1950, Caja 33, Carpeta 4). La H.I.W. se comprometió a enviarle e instalarle la maquinaria adquirida por valor de 3,5 millones de dólares, CIF Buenaventura, con una financiación a dos años. Phanor Eder, radicado en Nueva York, se constituyó en el representante legal de la sociedad en esa ciudad. (AHLM, Acta 28, abril 1950, caja 33 Carpeta 4).

En el mes de noviembre arribó al puerto de Buenaventura desde Nueva York el ingeniero enviado de la H.I.w. para el montaje de la nueva maquinaria. Para entonces se encontraban en las bodegas del puerto de Buenaventura unas 300 toneladas de materiales de la fábrica. El transporte de la maquinaria desde Buenaventura hasta Palmira y el montaje de la fábrica demoró aproximadamente año y medio, por las dificultades en el transporte de maquinaria pesada a través de la cordillera (AHLM, Acta 65, 1 de septiembre de 1952, Caja 33 carpeta 6).

La capacidad de molienda de la nueva fábrica era de 1.500 a 1.600 toneladas de caña por día, es decir, entre 85.000-95.000 toneladas métricas de caña por año, lo que duplicaba la molienda de la fábrica en 1940. La capacidad de molienda instalada entre 1908-1909 en el Ingenio de Sincerín, cerca de Cartagena, había sido la que ahora (1952) tenía La Manuelita, de 1.500 toneladas en 24 horas. Este ingenio 
costeño que en la década de los años veinte era el más moderno del país, en 1952 había decretado su cierre mientras entraban en liquidación sus últimos bienes. ${ }^{20}$

La nueva fábrica de La Manuelita inició operaciones en febrero de 1953, poniendo en el mercado por primera vez en Colombia azúcar refinada; Manuelita en 1953 no solo innovó con un nuevo producto, como era el azúcar refinada; también lo hizo con una nueva tecnología, un proceso de filtración con carbón animal, o carbón de hueso, hasta entonces un procedimiento desconocido en Colombia (AHLM, Caja 25 carpeta 14, carta fechada 26 de febrero de 1951).

Los avances iniciales en producción y rendimiento de la caña en Manuelita se aprecian en el Cuadro 6:

\section{CUADRO 6}

Producción y rendimiento en La Manuelita, antes y después de la ampliación de su capacidad instalada, 1952-1956

(plazas y toneladas métricas)

\begin{tabular}{|c|c|c|c|c|}
\hline Año & Caña sembrada & $\begin{array}{c}\text { Caña cosechada } \\
\text { t.m. }\end{array}$ & $\begin{array}{c}\text { Promedio caña } \\
\text { por plaza t.m. }\end{array}$ & $\begin{array}{c}\text { Rendimiento } \\
\text { promedio }\end{array}$ \\
\hline 1952 & 3.182 plazas & 230.675 & 72 caña/plaza & $11,61 \%$ \\
\hline 1953 & 3.805 plazas & 282.000 & 74 caña/ plaza & $11,71 \%$ \\
\hline 1956 & - & 350.164 & 90 caña/plaza* & $12,65 \%$ \\
\hline
\end{tabular}

* $89,58 \%$ en la fuente original, la aproximación a $90 \%$ es de la autora.

Fuente: Eder, 1959, pp. 298-99 y 599.

Obsérvese que, en 1956, tres años después de la puesta en marcha de la nueva fábrica, el promedio de la caña cosechada por plaza se incrementó de 72 a 90 toneladas métricas, 18 toneladas de diferencia con la de 1952, y el rendimiento promedio subió de 11,61 al 12,65\%.

Con motivo del montaje de la primera planta refinadora de azúcar del país la revista Semana publicó un artículo especial sobre La Manuelita con la imagen de Harold Eder en la portada de la edición del 30 de junio de 1951. También publicaron fotografías aéreas del ingenio las revistas de circulación norteamericana,

\footnotetext{
${ }^{20}$ Sobre las causa de su liquidación, véase Ripoll (2007).
} 
The Sugar Journal de New Orleans, y la revista International Sugar Journal, con descripción de la fábrica y fotografías (AHLM, Caja 25 carpeta 14). En mayo de 1953, el Presidente de la República (e), Roberto Urdaneta Arbeláez recibió el primer saco de azúcar refinada producido en Colombia, mostrándose muy emocionado y agradecido en su felicitación a Harold Eder.

\section{E. La productividad de la industria azucarera colombiana, 1980-2006}

La industria azucarera avanzó notablemente en su productividad (toneladas de azúcar por hectárea) a fines del siglo XX, gracias a sus constantes experimentaciones sobre variedades de caña más productivas, lo que permitió obtener mayores rendimientos sin necesariamente expandir el área de cultivos. En la Gráfica 2 se muestra el incremento del rendimiento azucarero en el Valle entre los años de 1980 y 2006. Allí vemos cómo en el transcurso de esos 25 años, se pasó de tener un rendimiento de 8,3 toneladas de azúcar por hectárea, (TAH), en 1980, a tener 13,3 TAH en el año de 2006, lo que es un rendimiento significativamente mayor de 5 TAH en 25 años.

Para poner en perspectiva estos indicadores conviene comparar la productividad promedio de la caña de azúcar y de la remolacha en otros países productores, incluida Colombia. Según estudios realizados por la firma inglesa L.M.C. International, (Informe Anual Asocaña, 2008-2009, p. 16) ${ }^{21}$ la productividad promedio de Colombia entre 1998 y 2002 fue de 12,8 TAH, la más alta entre 14 países productores de azúcar, mientras que el país que ocupó el segundo lugar (Australia) registró un rendimiento promedio de 10,6 TAH (Gráfica 3). La edad de maduración de la caña al corte varió, según la variedad.

Si bien en Australia se han alcanzado rendimientos hasta de 16,3 TAH, ello se logró con cañas de 17 meses de edad al corte, mientras que en Colombia los rendimientos alcanzados han llegado hasta 16,4 TAH, en cosechas en las que la edad de la caña al corte era de 14,7 meses (Luna et al., 1995, p. 383).

Recientemente el programa de variedades de Cenicaña Colombia, (c.c.), desarrolló un enfoque innovador conocido como Agricultura Específica por Sitio,

\footnotetext{
${ }^{21}$ L.M.c. International es una compañía privada fundada en 1980, proveedora de análisis de mercados a compañías y organizaciones del mundo relacionadas con productos agrícolas, comida, materiales industriales, bio-combustibles, entre otros. L.M.C. es enteramente independiente, y no comercia, no financia, ni produce ningún comodito. Tiene oficinas en Oxford, Nueva York, Los Ángeles, Singapur y Kuala Lumpur (Sobre la L.M.C. la información proviene de Wikipedia, consultado en junio 2018).
} 


\section{GRÁFICO 2}

Colombia: Productividad de la caña y del azúcar, 1980-2006

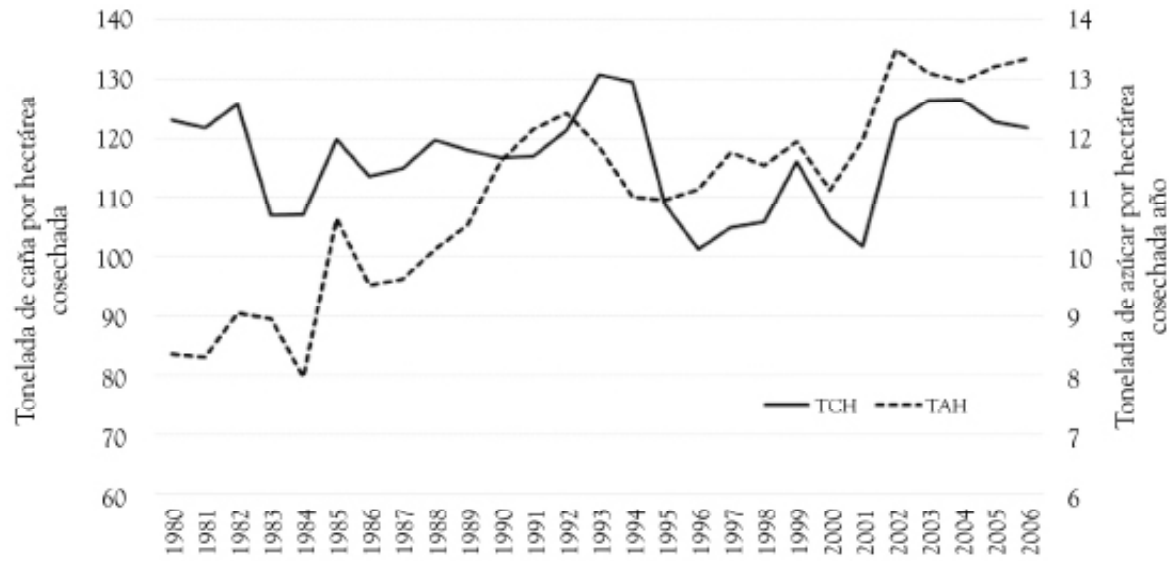

Nota: Hasta 1985 la información corresponde a una muestra de 11 ingenios que representaban el 96\% del azúcar producido. A partir de 1986 la muestra incluye todos los ingenios del valle geográfico del río Cauca que producen $99,7 \%$ del total.

Fuente: Cenicaña.

\section{GRÁFICO 3}

Producción de azúcar por hectárea, varios países, 1998-2002

(promedios)

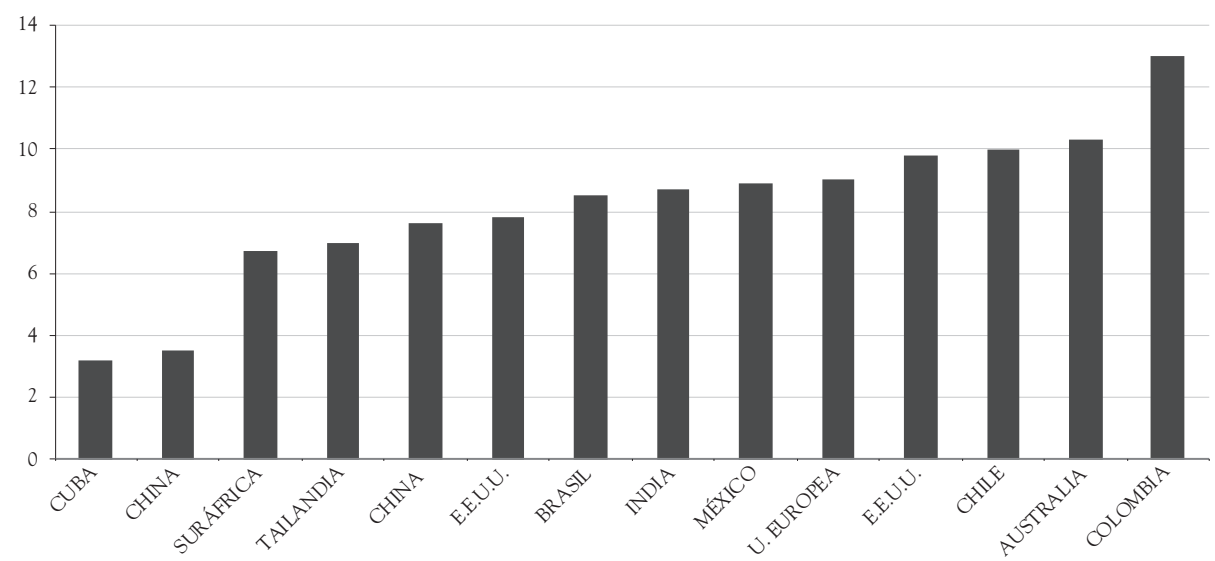

Nota: Para China, EE. UU., Unión Europea y Chile, azúcar de remolacha; para el resto, azúcar de caña.

Fuente: L.M.C. International. 
A.E.P.S., mediante el cual se identifican las condiciones agro-ecológicas particulares de cada cultivo de caña para aplicar las prácticas agronómicas adecuadas a cada condición, según afirmó Camilo Isaacs, Jefe del Servicio de Cooperación Técnica de Cenicaña: "Está demostrado que todo lo que se hace con este enfoque disminuye los costos, mejora la rentabilidad en las fincas y es ambientalmente responsable", dijo Isaacs. ${ }^{22}$ Es decir, la región dejó de ser percibida como una con condiciones agrícolas homogéneas.

\section{INVERSIONES COLECTIVAS DE LOS DUEÑOS DE INGENIOS, 1960-1970}

Los dueños de ingenios del Valle del Cauca en varias oportunidades se asociaron para compartir riesgos en situaciones específicas que requerían del aporte colectivo de la producción de azúcar o de las mieles residuales. En la década de 1930, como ya se dijo, crearon la Compañía Distribuidora de Azúcares, una comercializadora para la equitativa distribución del mercado interno. Más adelante se asociaron con propietarios de tierras en el Tolima para el montaje del ingenio Central Tolima, cerca de la población de Pajonales. En 1963 se asociaron en el montaje del Ingenio del Cauca, y a fines de la década de 1960, varios dueños de ingenios protocolizaron un Pacto Multilateral de Productores de Azúcar, para unir esfuerzos con el fin de exportar excedentes a Estados Unidos. De nuevo se asociaron a mediados de los sesentas en la inversión de dos empresas, Sucroquímica y Colmieles, que utilizaban como insumo las mieles residuales de los ingenios en la producción de químicos y en la exportación de las mieles. En este apartado el tema central es el estudio de estas inversiones colectivas en la que participan los principales ingenios del Valle.

\section{A. La creación del Ingenio del Cauca}

La creación del Ingenio del Cauca se debió a una iniciativa de La Manuelita, cuando a fines de 1962 su presidente, Harold Eder Caicedo, llegó a un acuerdo con varios propietarios de tierras del norte del departamento del Cauca, colin-

\footnotetext{
${ }^{22}$ Entrevista a Camilo Isaacs, publicada en Carta Informativa, noviembre 9, 2018. Camilo Isaacs fue reemplazado por Fernando Villegas Trujillo desde junio del 2018.
} 
dantes con tierras del sur del departamento del Valle, para la creación de un nuevo ingenio azucarero que molería caña comprada y caña propia. ${ }^{23} \mathrm{El}$ acuerdo consistió en aportes de las dos partes: Manuelita S.A. aportó dinero, y el equipo azucarero (usado pero en muy buen estado) que había quedado obsoleto después de la ampliación que se hizo de La Manuelita; estos equipos fueron avaluados por una firma extranjera en 15 millones de pesos. Los dueños de haciendas que aportaron tierras recibieron en dinero la mitad del valor de sus tierras y la otra mitad en acciones del Ingenio del Cauca.

La distancia desde Cali, capital del departamento del Valle, al Ingenio del Cauca, por carretera, era de unos 46 kilómetros (AHLM, Caja 21, Carpeta 22). La inversión total realizada en el Ingenio del Cauca fue de 150.000.000, millones de pesos, más 70.000.000, millones para pagar a los proveedores de caña. (AHLM, Caja 21, carpeta 22). Las formas de financiación fueron varias, y provinieron de distintas entidades, como lo señala el Cuadro 7.

\section{CUADRO 7}

Algunas fuentes de financiación del Ingenio del Cauca

\begin{tabular}{|c|c|l|}
\hline Año & Préstamos & \multicolumn{1}{|c|}{ Entidad } \\
\hline jul-63 & $\$ 20$ millones & Fondo de Inversiones Privadas \\
\hline oct-64 & Us $\$ 500.000$ & Import Export Bank \\
\hline 1965 & $\$ 7$ millones & Corporación Financiera Nacional \\
\hline 1965 & $\$ 5$ millones & Corporación Financiera Nacional \\
\hline mar-65 & $\$ 2$ millones & Banco del Comercio de Cali \\
\hline may-65 & $\$ 2$ millones & Banco de Bogotá de Cali \\
\hline may-65 & $\$ 1$ millón & Banco Comercial Antioqueño \\
\hline jun-65 & us $\$ 250.000$ & (ND) \\
\hline jun-65 & $\$ 5$ millones & Corporación Financiera Nacional \\
\hline jul-65 & $\$ 2$ millones & Banco Industrial Colombiano \\
\hline
\end{tabular}

Fuente: AHLM, Caja 33 carpeta 19, Acta No. 284; AHLm, Caja 33, carpeta 19, Actas Nos. 289, 290, 291, 292, 293, 294.

${ }^{23}$ La Sociedad Ingenio del Cauca se protocolizó el 29 de julio de 1963 por escritura pública No. 1.425 de la Notaría 1 de Palmira. AHLM Caja 30 carpeta 19. 
El Gerente del Ingenio del Cauca se quejaba del proceso dispendioso que requería reunir el capital financiero para los negocios; en el caso del nuevo ingenio les había tomado más de un año la consecución de fianzas bancarias, cartas de crédito irrevocables, obtención del seguro contra riesgos políticos de parte de los exportadores de Estados Unidos, y del crédito extranjero con el Foreign Credit Insurance Association, entre muchas otras exigencias. (AHLM, Caja 12, Carpeta 41). Todavía en agosto de 1965, hacía falta una suma calculada en 17.861.757, para la terminación del montaje del Ingenio.

La excesiva tramitología en la financiación de proyectos estaba relacionada con la política económica proteccionista de industrialización por sustitución de importaciones, que se acentuó en 1958 al inicio del Pacto del Frente Nacional, (1958-1974), y con las varias reformas arancelarias que se llevaron a cabo durante las administraciones de los años sesenta, reformas que incidieron en los intermediarios financieros y en las importaciones de bienes de capital. La obtención de créditos en las corporaciones financieras así como la obtención de los registros de importación de maquinaria, que otorgaba la Superintendencia de Comercio Exterior, eran diligencias sujetas a una tramitología exhaustiva que dificultaba cualquier previsión sobre el inicio del funcionamiento de proyectos productivos, ocasionando perjuicios en los casos de inversiones agroindustriales, como la del Ingenio del Cauca (Ocampo et. al., 1994).

Faltándole aún algo del equipo no esencial, el nuevo Ingenio inició pruebas de la maquinaria sin la caña, y gracias al éxito obtenido pudo iniciar su programa de molienda efectiva a mediados del mes de marzo de 1966. Su capacidad de molienda inicial era de 1.200 toneladas de caña cada 24 horas; mas sin embargo sus estructuras y diseños permitían elevar tal capacidad a 5.000 toneladas mediante un equipo adicional. Para ese entonces la capacidad de molienda de La Manuelita había aumentado a 2.600 toneladas al día. La planeación y supervisión del montaje del Ingenio del Cauca estuvo a cargo de personal técnico de la firma Sucesores de Abarca, de Puerto Rico.

La fábrica del nuevo Ingenio combinaba equipos importados (25\%) con elementos fabricados en el país en la Siderúrgica Medellín; a ello había que agregar una buena parte de la maquinaria del viejo Ingenio Manuelita y la casi totalidad de la del Ingenio Central Tolima, en Pajonales, este último inactivo desde 1958 y que había operado por poco tiempo. Poner en funcionamiento esta amalgama de equipos de distinta procedencia fue el resultado de la inventiva de sus gestores y administradores, unida a los servicios de planeamiento y supervisión de la firma 
Sucesores de Abarca, quienes de esa manera habían contribuido no sólo al ahorro de divisas al país sino también a la utilización y recuperación de un equipo azucarero que estando en buen estado había quedado en desuso.

El programa de siembras de caña para el ingenio del Cauca que se inició en 1964 cubría 13.200 plazas (8.000 hectáreas) en el momento de su puesta en marcha en 1966, de las cuales 3.500 plazas eran propiedad de la Sociedad y el resto de colonos proveedores de cañas, a quienes se les liquidaba de acuerdo con el rendimiento azucarero de las cañas. Esta modalidad de provisión permitió que los dueños de tierras cañeras fueran incorporados al negocio como proveedores de materia prima.

En 1966 el Ingenio del Cauca tenía alrededor de 110 empleados, entre ejecutivos y directivos, personal de fábrica y oficinas, y más de 2.000 trabajadores de campo, fábrica y talleres. Se calculaba que cuando el Ingenio estuviese operando a plenitud tendría un personal de cerca de 5.000 personas, incluidos los colonos.

\section{B. Colombiana de Mieles S.A., Colmieles}

En la década de 1960 los dueños de ingenios del Valle se asociaron para crear dos empresas, Colmieles y Sucroquímica, con el objeto de utilizar provechosamente los insumos derivados del procesamiento de la caña de azúcar, uno de ellos las llamadas mieles residuales.

Antes de la creación de estas empresas los excedentes de mieles residuales de los ingenios azucareros no tenían uso alguno, y muchas veces eran arrojados a los caños de riego de los ingenios, como la única solución, lo que significaba no sólo un desperdicio sino también la contaminación de las aguas, incluido los ríos mayores, inhabilitándolas para el riego y para el uso de las poblaciones vecinas. Por ello la exportación de estas mieles residuales al mercado internacional resultó la mejor solución puesto que además de resolver un problema, significaba un aporte más de la industria azucarera al ingreso de divisas extranjeras en la economía nacional. (Анцм, Caja 47, carpetas 1, 4, 5)

Quince ingenios del Valle se asociaron en este negocio, en el que el capital suscrito y pagado de la compañía fue de $\$ 10.470 .000$; el capital por suscribir $\$ 530.000$; y el capital total autorizado era de once millones de pesos. (Анцм, Caja 47, carpeta 4). Los ingenios de mayor capacidad de producción, (La Manuelita, Central Castilla, Providencia y Riopaila) suscribieron el 54,55 por ciento de las acciones de la compañía. 
Las inversiones que los accionistas habían hecho para el aprovechamiento de las mieles residuales en julio de 1968 superaban los $\$ 16.000 .000$, y consistían en una planta de recolección vecina a Palmira, planta de exportación en el puerto de Buenaventura, equipo férreo (vagones) para el transporte de las mieles, plataforma y cisternas de propiedad de Colmiel y sistemas de bombeos específicos. (AнLM, Caja 47, carpeta 5).

Todo el sistema de transporte indispensable para la exportación de estas melazas, incluidas la infraestructura portuaria adecuada, fue sufragada en su totalidad por los ingenios azucareros del Valle del Cauca, sin la participación de organismos oficiales. Con frecuencia había quejas de los azucareros por la falta de cooperación del gobierno a sus iniciativas, aun en cosas básicas como era la inversión en muelles en Buenaventura, único puerto sobre el Pacífico colombiano, viéndose obligados los azucareros a suplir esas necesidades. Los costos del transporte de las mieles, por ejemplo, eran el mayor problema que tenía la industria. En 1969 el Gerente de Colmieles declaró que en seis meses aún no había conseguido que la empresa oficial, Puertos de Colombia, definiera las tarifas para las exportaciones de mieles. (AHLM Caja 47 carpeta 3). Mientras en mayo de 1969 Ferrocarriles Nacionales ${ }^{24}$ sin previo aviso subió la tarifa del transporte de mieles en 21 pesos, (pasó de \$ 46 a 67 pesos) habiéndola subido el año anterior.

El desarrollo de las actividades de Colmieles beneficiaba a Colombia no solo por generar divisas; también era fuente de trabajo pues beneficiaba al transporte automotor, (camiones-tanques), y a Ferrocarriles Nacionales, así los vagones o unidades férreas fueran de propiedad de los ingenios. En el puerto de Buenaventura eran los compradores extranjeros quienes contrataban los buques tanque para llevarse la carga de mieles, y eran ellos los que debían tener en cuenta las tarifas por fletes para favorecer a sus empresas. Además, cada exportación significaba pagos de derechos, servicios, honorarios a Puertos de Colombia, a la aduana y a los agentes de aduanas. A ello habría que sumar el pago en servicios públicos, servicios marítimos, fletes, seguros etc.

El cliente principal de Colmieles en Estados Unidos era la compañía National Molasses Co., quien desde 1968 suscribió un contrato con Colmieles para la adquisición de toda la producción entre 1968-1970, con un anticipo de U.s.\$300.000,00.

\footnotetext{
${ }^{24}$ Ferrocarriles Nacionales de Colombia fue una empresa creada en 1954 por el gobierno nacional para unificar en una sola entidad el sistema ferroviario nacional, que hasta la fecha estaba compuesto de varias empresas locales administradas por las regiones. Operó hasta 1991 cuando por problemas financieros se liquidó.
} 
National Molasses era una subsidiaria de C. Brewer and Co. Ltd., de Honolulu, Hawái. (AHLM, Caja 47 carpetas 4, y 5).

Sobre la trayectoria de esta compañía norteamericana, es muy diciente una carta del Gerente de compras de National Molasses para el Gerente de Colmieles, fechada en agosto de 1968, en la que le dice, entre otras cosas:

(...) Tenemos contratos que cubren la mayor parte de las mieles disponibles para exportación de Sur y Centroamérica, incluyendo todas las mieles exportadas del Ecuador, Panamá, Costa Rica, Guatemala y el 85 \% de las exportadas por México y de otros productores del mundo incluyendo el volumen de las mieles australianas (...) Nuestra casa principal es la mayor productora de azúcar y mieles de Estados Unidos. (AHLM Caja 47 carpeta 5).

La importancia de este negocio se puede apreciar en el Cuadro 8 que muestra la producción, el consumo y la exportación de mieles entre 1974 y 1986. Allí vemos que el valor de las exportaciones entre 1974 y 1986 ascendió a un total de us $\$ 73.272 .000,00$ una suma nada despreciable.

\section{Sucroquímica Colombiana s.A.}

La creación de esta compañía fue considerada como una de las más inmediatas respuestas del sector privado al Plan de Desarrollo Económico propuesto por el gobierno de Alberto Lleras Camargo, (1958-1962), en el capítulo de Incentivos Tributarios de la Reforma Fiscal. En virtud de la Ley 81 de 1960 y decretos complementarios, Sucroquímica Colombiana s.A., en su condición de industria básica, obtuvo para sus accionistas una exención del 100\% de impuestos sobre la renta, patrimonio y complementarios hasta el año de 1969 (AHLM, Caja 30, carpeta 17).

Sucroquímica Colombiana S.A. fue creada en 1962 como una sociedad anónima con un capital autorizado de 25 millones de pesos, representado en 2.500 .000 acciones a diez pesos cada una. ${ }^{25}$ De ellas se hallaban suscritas 1.960 .490 y pagadas 1.670.094, quedando 539.510 acciones por suscribir.

Sólo cinco ingenios suscribieron acciones: Manuelita, Mayagüez, Providencia, Central Tumaco y Pichichi (AHLM, Caja 30 carpeta 17). Al momento de su creación

${ }^{25}$ Escritura No. 3.392 de 27 de junio 1962, Notaría 1, Cali; Escritura No. 6.385 de 5 de noviembre 1962, Notaria 1, Cali. 
CUADRO 8

Colombia: Producción, consumo y exportación de mieles, 1974-1986

\begin{tabular}{|c|c|c|c|c|}
\hline Año & $\begin{array}{c}\text { Producción } \\
\text { (tons.) }\end{array}$ & $\begin{array}{c}\text { Consumo } \\
\text { (tons.) }\end{array}$ & $\begin{array}{c}\text { Exportación } \\
\text { (tons.) }\end{array}$ & $\begin{array}{c}\text { Valor exportado } \\
\text { (Us\$) }\end{array}$ \\
\hline 1974 & 264.560 & 227.045 & 27.625 & 1.669 \\
\hline 1975 & 286.652 & 231.988 & 40.845 & 1.759 \\
\hline 1976 & 276.312 & 212.760 & 92.718 & 4.589 \\
\hline 1977 & 236.750 & 200.054 & 37.843 & 1.260 \\
\hline 1978 & 288.963 & 172.135 & 113.774 & 5.200 \\
\hline 1979 & 318.177 & 159.041 & 161.905 & 10.445 \\
\hline 1980 & 361.270 & 198.600 & 159.935 & 18.248 \\
\hline 1981 & 341.920 & 220.761 & 106.913 & 9.311 \\
\hline 1982 & 362.960 & 229.935 & 133.025 & 4.929 \\
\hline 1983 & 401.065 & 265.943 & 127.275 & 6.930 \\
\hline 1984 & 351.165 & 295.315 & 51.398 & 2.866 \\
\hline 1985 & 348.593 & 273.999 & 76.950 & 3.266 \\
\hline $1986(1)$ & 327.150 & 259.215 & 40.000 & 2.800 \\
\hline Total & 4.165 .537 & 2.946 .791 & 1.170 .186 & 73.272 .000 \\
\hline
\end{tabular}

(1) Cifras para 1986 son estimativos de Colmieles. Se tomó un valor exportado de u.s. \$ 70.00 / tonelada para 1986.

Fuente: AHLM, La industria azucarera en Colombia, Caja 39, carpeta 4, p. 18.

la Junta Directiva estaba compuesta en su mayoría por dueños de ingenios o sus administradores, entre los cuales se encontraba Harold Eder Caicedo.

La fábrica de Sucroquímica se ubicó en una zona a 2,5 kilómetros de Palmira, contigua a las instalaciones de la Compañía Colombiana de Mieles S.A., abastecedora de mieles que eran la principal materia prima de Sucroquímica, facilitando su abastecimiento por un sistema de bombeo directo que reducía considerablemente los costos del transporte de mieles.

El objetivo de Sucroquímica era la explotación gradual de químicos obtenidos de un subproducto de la industria azucarera como son las mieles; los primeros químicos producidos fueron el ácido cítrico y el ácido acético, como base del desenvolvimiento de la empresa (AHLM Caja 30 carpeta 17). 
El proyecto de la planta de ácido cítrico fue encomendado en 1963 a una firma alemana especializada en ese campo, la Standard-Messo Duisburg, de Duisburg, que tuvo a su cargo el suministro del equipo necesario para la planta, así como el proceso, las cepas, las técnicas, y la asistencia necesaria para su puesta en marcha. El gobierno y la Superintendencia Nacional de Importaciones facilitaron los trámites de importación y nacionalización de todos los equipos y plantas, habida cuenta de los beneficios que la empresa le reportaría al país (АНLM Caja 30 carpeta 18, Acta Asamblea General, febrero 1964).

Los empresarios del Valle fueron innovadores en la introducción al país de esta fábrica y esta producción pues la industria Sucroquímica era desconocida en Colombia. En el proceso de montaje debieron estudiar sobre qué líneas de los derivados del acetaldehído producir. Tanto el ácido acético, como la acetona, acetato de vinilo y acetato de etilo, tenían un mercado en el país que se abastecía con importaciones que serían sustituidas por la producción nacional, con la posibilidad de exportar excedentes (AHLM Caja 30 carpeta 18).

Lastimosamente Harold Eder Caicedo no viviría para ver los resultados finales de los que fueron sus últimos proyectos: Ingenio del Cauca, Colmieles y Sucroquímica, en los que había puesto tanto empeño. Un grupo de maleantes, presuntamente guerrilleros de las FARC, lo secuestró el 20 de marzo de 1965, en su Hacienda Quebradaseca (Cauca), al parecer hiriéndolo gravemente. Su muerte, confirmada el 12 de abril, 23 días después de su secuestro, conmocionó a Colombia entera. La Junta Directiva de Manuelita al iniciar sus labores ese día dejó constancia del gran pesar que embargaba a sus miembros, por la desaparición de quien fuera presidente de la Compañía (Acta No. 291, La Manuelita, caja 33, Carpeta 19).

Harold Eder Caicedo había sido el artífice en la consolidación de la sociedad familiar; el responsable de la multiplicación del capital y de su manejo acertado; el de las grandes iniciativas de proyectos viables de modernización de esta industria, y uno de los innovadores más eficientes: innovador en el mercado con un nuevo producto, como fue la azúcar refinada; innovador en la producción, con la participación que tuvo en la introducción al país de la industria Sucroquímica. Innovador en los procesos de producción, con el uso de nuevas tecnologías. Un busto de Harold Eder Caicedo se erigió en su memoria cerca de la entrada de la Capilla de la Hacienda, y un retrato al óleo suyo se colgó en el salón de la empresa junto con los óleos de su abuelo, de su tío Carlos y de su padre. 


\section{El liderazgo regional de Henry Eder Caicedo}

Ante la inesperada muerte de Harold Eder correspondió a su hijo Henry asumir la dirección de la empresa y de los negocios de la familia. ${ }^{26}$ Su trayectoria en la empresa se destacó por la diversificación del portafolio de inversiones que llevó a cabo, que incluyó la internacionalización de los intereses económicos de la empresa. Pero su gestión no se limitó a los intereses familiares; Henry tenía vocación de servicio en el sector público y el privado. Inicialmente lo hizo desde el Consejo (1978-1980) y la Alcaldía de Cali, (1986-1988), y posteriormente en la Corporación Autónoma Regional del Valle del Cauca, c.v.c. (1967-1977). A continuación, se describe su desempeño tanto en el sector público como sus aportes en La Manuelita, siendo Henry la tercera generación de los Eder al frente de la empresa familiar.

Henry, al igual que su padre, a los 13 años fue enviado a estudiar al Choate School en Connecticut, (AHLM, caja 3 carpeta 2); más tarde estudió Ingeniería Eléctrica en el Massachusetts Institute of Technology (MIT). Un rasgo común entre los Eder que han estado al frente de la empresa familiar ha sido su sólida formación profesional, lo que podía haber sido requisito indispensable en el protocolo de manejo de la empresa familiar.

A su regreso a Colombia, entre 1959 y 1960, se integró a la misión de estudios del Valle del Magdalena, dirigida por Lauchlin Currie, bajo la Presidencia de Alberto Lleras Camargo, (1958-1962). Después de esta experiencia en el sector público, Henry hizo estudios de economía en London School of Economics, y a su regreso a Colombia, en 1962, entró finalmente a trabajar en La Manuelita como asistente del presidente.

Henry Eder no quiso ocupar la Presidencia de la compañía después de la muerte de su padre, y prefirió dirigirla desde la Junta Directiva, en la que se mantuvo muy receptivo a las decisiones de los ejecutivos que habían hecho parte de la administración de su padre durante más de 30 años, y en quienes delegó la Presidencia de la compañía. Estos profesionales fueron Alberto Bernal Correa, Presidente de

${ }^{26}$ Henry Eder Caicedo tiene dos hermanas mayores. Nació en Cali, en 1935, y pasó su niñez en la hacienda La Rita vecina del Ingenio bajo la instrucción de una institutriz inglesa. Parte de los datos personales de Henry en esta sección fueron tomados de la entrevista que le hicieran con motivo de su elección para Premios Portafolios en la categoría Vida y Obra Empresarial, en Portafolio, 1 de diciembre 2017, p. 12, complementados con una breve entrevista que le hiciera Caracol TV en enero de 2019. 
La Manuelita entre 1965 y 1982; Jaime Zambrano Campo, presidente entre 1982 y 1991; Alberto Anzola Jiménez, presidente entre 1991 y 1993; y César Zamorano Estrada, entre 1993 y 2008. Estos ejecutivos son testimonio de la separación que hubo entre propiedad y gestión administrativa en el manejo de La Manuelita. Con la valiosa experiencia que acumularon, estos ejecutivos contribuyeron a la continuidad administrativa en la empresa de familia, una vez desaparecido Harold, y a una transición de mando sin conflictos internos. César Zamorano, el único que no formó parte del equipo de Harold, trabajó 41 años en La Manuelita, y ocuparía la Presidencia entre 1993 y 2008, siendo el último de los presidentes de la empresa sin vínculo de consanguinidad con Cesar Zamorano, el único que no formó parte del equipo de Harold Eder. En 2008, le sucedió en el cargo Harold Eder Garcés, hijo de Henry, quien ha presidido la empresa hasta el presente.

Henry Eder se retiró temporalmente de La Manuelita en 1967 para asumir la dirección ejecutiva de la Corporación Autónoma Regional del Cauca, C.V.c., de la que su padre había sido socio fundador, en donde permaneció por espacio de diez años.

Los primeros proyectos de la c.V.C., entre 1955 y 1962, bajo la administración de Bernardo Garcés Córdoba, proponían la recuperación de tierras inundables en el Valle del Cauca con el fin de llevar a cabo una redistribución y el reasentamiento de campesinos pobres en lotes más grandes de tierras de cultivo. ${ }^{27}$ Es decir, los primeros planes contemplaban principalmente beneficios sociales y materiales para el campesinado.

Con la sanción de la Ley de Reforma Agraria, en 1961, los organizadores de la C.V.C. reorientaron sus prioridades, al desviar la atención de los proyectos para familias campesinas, a programas dirigidos a obtener la eficiencia en la producción agrícola y la generación de empleo. Aspiraban a trabajar con tenedores o arrendadores de fincas medianas y grandes, con cultivos agrícolas, con el fin de aumentar su productividad (Jackson, 1972, p. 195). Esta política se acentuó con la llegada de Henry Eder como director ejecutivo de la C.v.c., a partir de 1967.

La visión que tenían los planificadores de la C.V.c. era la de una organización capitalista más orientada al incremento de la producción agrícola a través de mejoras en el manejo de las fincas. Para la c.v.c. el reto principal era el crecimiento

${ }^{27}$ Me refiero al proyecto de Aguablanca, construido entre 1958 y 1962, y el de Roldanillo-La Unión-Toro, (R-U-T), iniciado en 1958 y adquirido por el Incora en 1962. Eran proyectos que contemplaban la construcción de diques, el drenaje y el control de inundaciones, con el objeto de recuperar tierras para beneficio de los campesinos: G. Jackson, 1972, pp. 165-176. 
económico, y la inversión privada era considerada un ingrediente vital. Bajar la tasa de desempleo era otro de sus retos fundamentales, visto como la solución a los problemas socioeconómicos de la región (Jackson, 1972, pp. 270-71).

Cuando el gobierno de Carlos Lleras Restrepo (1966-1970) creó el Inderena, una entidad adjunta al ministerio de Agricultura para la conservación de los recursos naturales, los líderes de la c.V.c. consiguieron que el gobierno delegara en la c.v.c. las funciones conservacionistas en el alto río Cauca, incluyendo aportes del presupuesto del Inderena. Henry Eder, además sumó a esta iniciativa la de un contrato entre la C.v.C. y la Caja de Crédito Agrario en el que la C.v.c. se comprometió a supervisar créditos a campesinos para avances en la agricultura. $\mathrm{Al}$ año de vigencia de este contrato 180 campesinos se habían beneficiado de los créditos de la Caja Agraria (Jackson, 1972, pp. 230-31).

Otros cambios durante la administración Eder se hicieron en el personal empleado, que pasó de tres personas en 1967, a 889 en 1972, y en el número de departamentos, que se incrementó de uno a ocho. Henry Eder llevó a cabo reformas dirigidas a involucrar al personal en decisiones administrativas y generar un sentido de compromiso de mayor productividad para la c.v.c. (G. Jackson, 1972: 338). Esta atmósfera reformista se completó con la presencia de un psicólogo industrial de planta para reforzar el compromiso de los empleados de la c.v.c. con el desarrollo económico regional. (Jackson, 1972, p. 340).

\section{E. Diversificación del portafolio e internacionalización de La Manuelita}

La gestión de Henry Eder en La Manuelita se centró en la diversificación del portafolio de la empresa con inversiones en otros sectores y en otras regiones del país; y la internacionalización del grupo empresarial con operaciones en cuatro países de América Latina: Perú, Chile, Brasil y Colombia. La Manuelita maneja en la actualidad cuatro plataformas agroindustriales que son: la caña de azúcar, que es la principal, seguida de aceites, frutas y hortalizas, y acuicultura, a lo cual nos referiremos brevemente en este apartado.

Aceites Manuelita inició su plan de diversificación con cultivos de palma de aceite en el departamento del Meta. En 1986, adquirió la hacienda Yaguarito, donde montó una planta para la producción de aceite de palma africana. En 2009 Aceites Manuelita montó una segunda planta en San Carlos de Guaroa, Meta, que inició operaciones en 2009. Hoy tiene 427 empleados y su producción anual es 
de, aproximadamente, 80,000 toneladas de aceite crudo de palma, 11,000 toneladas de glicerina refinada y 125,000 toneladas de biodiesel. Una tercera inversión en la producción de biocombustibles la hizo en Palmar de Altamira, en Orocué (departamento de Casanare), también con base en el cultivo y procesamiento de la palma de aceite. La palma de aceite y la caña son cultivos muy eficientes en la producción de biomasa para generar energía eléctrica, un negocio en el que La Manuelita piensa ingresar en el futuro próximo.

Una más reciente inversión en la producción de biocombustibles fue la que hizo en Brasil, en Vale do Paraná, Sao Paulo, una compañía formada en un 50 por ciento por Unialco, de Brasil; 25 por ciento de Pantaleón Sugar Holdings de Guatemala, y 25 por ciento de Manuelita. Parte de la financiación estuvo a cargo de International Finance Corporation, del Banco Mundial. El proyecto Vale do Parana inició operaciones en 2008 para la producción de etanol, con base en un volumen de 1.700.000 toneladas de caña anual. Brasil, como es bien sabido, es el principal productor mundial de azúcar, de etanol y de energía eléctrica desde sus ingenios (Portafolio, diciembre $1^{\circ}$ de 2006, p. 20).

También invirtió La Manuelita en acuicultura. En 1987 adquirió la compañía Océanos, en Cartagena, tal vez la mayor productora de camarones en cultivo en Colombia. Océanos en 2014 producía 7.000 toneladas anuales de camarón, y contaba con 365 empleados. Otra inversión en el sector de alimentos fue la que hizo en 2007 en Mejillones América, con cultivos para la exportación, en Puerto Montt, Chile. Ese mismo año Manuelita inició la producción de frutas y hortalizas en Ica, Perú, desde donde exporta su producción de uvas de mesa, y más recientemente espárragos. Cuenta con 158 empleados.

Una de las primeras inversiones en el exterior la hizo La Manuelita en 1998, en la industria azucarera peruana. Esta industria había sufrido un revés, pues el país pasó de exportar más de la mitad de su producción, en 1970, a ser importador en las dos últimas décadas del siglo xx. La crisis en la producción de la industria azucarera peruana se debió a la cooperativización de sus ingenios en 1968, por el gobierno militar de Juan Velasco Alvarado (1968-1974), una política económica que fue continuada por su sucesor. Como resultado de esta medida, a fines de los años setenta los productores de esas cooperativas azucareras enfrentaron crecientes problemas externos e internos, con lo cual se descapitalizaron y perdieron presencia en los mercados mundiales (Zegarra, 2004, p. 53).

El cambio en la política azucarera peruana, hacia 1995, que inició el presidente Alberto Fujimori (1990-2000), permitió la entrada de capital privado a las coope- 
rativas. Con el cambio de modelo empresarial los ingenios peruanos se convirtieron en sociedades anónimas con inversión privada a través de la compra de acciones. Entre los nuevos socios, siete eran de grupos económicos peruanos y solo uno extranjero: La Manuelita, al adquirir el 64,2 por ciento de las acciones de la Empresa Agroindustrial Laredo, en 1998 (Inga, 2003, p. 69).

La empresa Agroindustrial Laredo S.A. está ubicada en el Valle de Santa Catalina, Provincia de Trujillo, en la costa norte de Perú. Al adquirir el 64,2 por ciento del capital social Manuelita tomó el control de la empresa, por un costo total de us $\$ 18$ millones. Un plan de inversiones de más de us\$50 millones permitió la puesta en marcha de la producción de azúcar refinada, con lo que la empresa no solo cubrió el consumo doméstico, también la demanda industrial de bebidas que se abastecían de azúcar importada (Inga, 2003, pp. 71-72).

Agroindustrial Laredo, en 2004, tenía una capacidad de molienda anual de 1.500.000 toneladas de caña, y una capacidad de producción de 175.000 toneladas de azúcar anuales. Los resultados favorables se reflejaron en los aspectos financieros. Las utilidades después de impuestos ascendieron en 2002 a 12 millones de soles, 12 por ciento más respecto a 2001 y 226,6 por ciento más respecto a 1999 . El patrimonio neto de la empresa, al 31 de diciembre de 2002 totalizó 155,9 millones de soles, 8,4 por ciento por encima del año anterior (Inga, 2003). ${ }^{28}$ En 2006, La Manuelita poseía el 79 por ciento de las acciones de este ingenio peruano, entonces el cuarto productor de azúcar del Perú. (Portafolio, septiembre 22 de 2006).

\section{PORTAFOLIO DE INVERSIONES DE LOS INGENIOS DEL VALLE DEL CAUCA, 2000-2015}

Los inicios del siglo XXI se caracterizan por grandes cambios en el sector azucarero vistos como un avance en esta agroindustria, tanto en el ámbito nacional como internacional. Al igual que en La Manuelita, el negocio medular de los ingenios del Valle del Cauca comenzó a desplazarse gradualmente del azúcar hacia productos con un mayor valor agregado. El sector azucarero buscaba una mayor integración y diversificación de su producción, dirigida básicamente a 1) generar

${ }^{28}$ En 2002, la tasa de cambio osciló entre 3,44 y 3,64 soles por dólar (Google Scholar, consultado enero 10 de 2019). 
productos con mayor valor agregado para disminuir la dependencia del azúcar; 2) aprovechar mejor los subproductos de la industria; 3) neutralizar así las fluctuaciones de precios del azúcar. "La estrategia de diversificación del portafolio era un blindaje a la volatilidad de precios del azúcar” (Millán, 2002, p. 31).

Dos coyunturas relacionadas entre sí en los primeros años del siglo XXI incidieron en la toma de decisiones del sector azucarero colombiano: el alza en los precios del petróleo y la revaluación del peso frente al dólar. Ambos factores afectaron de distinta manera al sector azucarero. La revaluación del peso implicó menores ingresos por concepto de exportaciones. La volatilidad del precio del azúcar, así como el alza mundial en los precios del petróleo posiblemente generó mayores expectativas entre los dueños de ingenios para invertir en la producción de biocombustibles a partir de la caña de azúcar.

Entre 2003 y 2008, período en que se inicia el programa y la producción de alcohol carburante en Colombia, el precio mundial del petróleo se cuadruplicó, alcanzando sus niveles más altos en 2008, cuando llegó a cotizarse a más de us $\$ 100$ el barril (Cepal, 2009). Para los dueños de ingenios del Valle, la producción de alcohol carburante a partir de la caña de azúcar representaba una alternativa viable para disminuir la dependencia del precio del azúcar, y al mismo tiempo la dependencia a los combustibles no renovables.

El beneficio ambiental del uso de oxigenantes en la gasolina, como el etanol, es reconocido mundialmente: la gasolina sin esta mezcla emite siete veces más gases efecto invernadero. Otra ventaja de la producción de biocombustibles es que son biodegradables: el 85 por ciento se degrada en aproximadamente 28 días, mientras que los combustibles fósiles pueden durar años en desaparecer. A estas ventajas medioambientales se le suma el gran potencial del etanol como producto de exportación y generador de divisas.

El apoyo del gobierno colombiano a este programa fue muy importante, a través de una normatividad basada en la obligación gradual de consumir combustible (gasolina automotora) con mezcla de etanol. La política de apoyo del gobierno estimuló la inversión del sector privado que ascendía a 900 millones de dólares en siete destilerías, con una producción anual de aproximadamente 367 millones de litros para el 2017 (El Tiempo, 29 julio 2018, p. 12). De las siete destilerías que existen en Colombia (2018) cinco son de los ingenios azucareros Manuelita, Incauca, Providencia, Mayagüez y Risaralda; entre todos tienen una capacidad total de producción de 1.050.000 litros diarios de etanol, que ya para 2011 abastecía el $60 \%$ del mercado interno (Pérez et. al., 2011, p. 154). En el Grafico 4 se muestra 


\section{GRÁFICO 4}

Producción y ventas de alcohol carburante (etanol) de los ingenios, 2005-2015

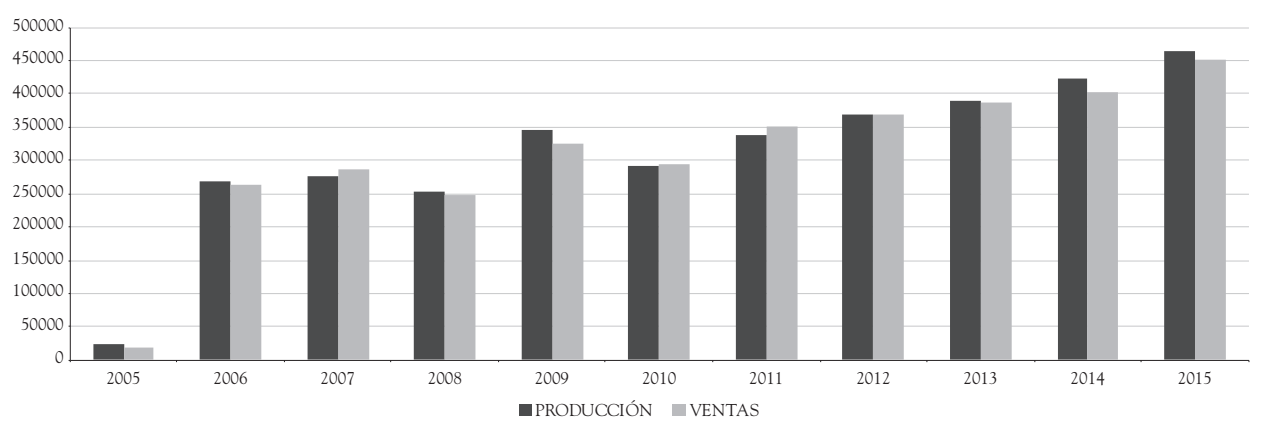

Fuente: Asocaña. Informe Anual 2014-2015.

la evolución paralela de la producción y ventas de etanol entre 2005, fecha en que se inicia este programa, y 2015

En el Cuadro 9 se muestran la evolución de la producción de etanol y sus ventas en las distintas regiones del país entre octubre de 2005 y 2013.

La capacidad instalada de las cinco destilerías existentes en los ingenios mencionados puede cubrir la mezcla decretada en el territorio nacional. No obstante, la gran expansión experimentada en Colombia en los últimos años en la producción de etanol, ésta sólo equivale a cerca del 2 por ciento de la producción total de Brasil. ${ }^{29}$

Desde 2008 el Grupo Empresarial Ecopetrol entró al negocio de los biocombustibles con cultivos de caña de azúcar en el municipio de Puerto López, Meta, en el proyecto "Bioenergy El Alcaraván”. Inicialmente utilizó tecnología patentada del Valle del Cauca. De otra parte, en el Centro de Investigación de la Caña, Cenicaña, se está trabajando en la producción de una supercaña que se adapte al medioambiente de los Llanos (Portafolio, 26, 27 enero 2019, p. 24).

En la actualidad, la planta Bioenergy El Alcaraván utiliza aproximadamente 50 por ciento de su capacidad instalada, que representa unos 50 millones de

\footnotetext{
${ }^{29}$ La información de este párrafo se basa en Toasa (2009, p. 9).
} 


\section{CUADRO 9}

Balance de la producción y ventas (litros) de alcohol carburante en Colombia 2005-2013

\begin{tabular}{|c|c|c|l|}
\hline Año & Producción & Ventas & \multicolumn{1}{c|}{ Área cubierta y mezcla } \\
\hline 2005 & 27.034 & 22.602 & $\begin{array}{l}\text { Valle del Cauca, Cauca, Nariño, Risaralda, Quindío. } \\
\text { Mezcla de 10\% }\end{array}$ \\
\hline 2006 & 265.684 & 262.470 & Bogotá y el centro del país. 10\% \\
\hline 2007 & 271.773 & 283.132 & Santanderes, sur del Cesar, norte de Boyacá. 10\% \\
\hline 2008 & 255.584 & 247.097 & Mezcla de 10\% \\
\hline 2009 & 327.705 & 338.360 & Huila, Tolima, Antioquia, Chocó. 10\% \\
\hline 2010 & 291.286 & 292.089 & $\begin{array}{l}\text { Llanos orientales, Putumayo, Caquetá, Costa Norte. } \\
\text { Mezcla de 8\% en todo el país }\end{array}$ \\
\hline 2011 & 337.398 & 351.086 & Mezcla del 10\% en sur y suroccidente \\
\hline 2012 & 369.722 & 368.446 & Mezcla de 8\% en todo el país \\
\hline 2013 & 387.859 & 393.782 & $\begin{array}{l}\text { A partir de noviembre mezcal de 10\% en Bogotá, centro, } \\
\text { suroccidente y sur del país. }\end{array}$ \\
\hline
\end{tabular}

La información de ventas (nacionales) corresponde exclusivamente a alcohol carburante (para mezcla con gasolina), que representa más del $99 \%$ de la producción de etanol. El porcentaje restante no incluido corresponde a alcohol para uso industrial.

Fuente: FEPA y cálculos Asocaña. Anexo Estadístico. Informe Anual Asocaña 2013-2014.

litros anuales de alcohol carburante. Se espera que en 2022 duplique su producción. Según Walfredo Linhares, presidente de la compañía, para eso necesita una molienda de 1,5 millones de toneladas de caña que se cosecharán entre 2021 y 2022, pues piensa aumentar el área sembrada de caña de 18,000 a 24,000 hectáreas. La planta se autoabastece de energía obtenida del procesamiento del bagazo de caña (Portafolio, enero 27 de 2019, p. 24).

\section{A. Cogeneración de energía a partir del bagazo de caña}

Al tiempo que se estudiaba la inversión en destilerías para la producción de alcohol carburante, se consideró la posibilidad de inversión en la cogeneración de energía a partir del bagazo de caña. "La cogeneración es un procedimiento mediante 


\section{CUADRO 10}

Colombia: Exportaciones de azúcar, 1974-1986 (toneladas métricas, valor crudo)

\begin{tabular}{|c|c|c|c|c|c|}
\hline Año & EEUU & $\begin{array}{c}\text { Mercado } \\
\text { mundial }\end{array}$ & $\begin{array}{c}\text { Export. } \\
\text { totales }\end{array}$ & $\begin{array}{c}\text { Vlr. export. } \\
\text { (Us\$ millones) }\end{array}$ & $\begin{array}{c}\text { Precio promedio } \\
\text { por t. Us\$ }\end{array}$ \\
\hline 1974 & 92.626 & 36.035 & 128.661 & 74,3 & 577,4 \\
\hline 1975 & 137.761 & 60.076 & 197.837 & 88,6 & 447,8 \\
\hline 1976 & 106.763 & 0 & 106.763 & 26,3 & 246,4 \\
\hline 1977 & 0 & 0 & 0 & 0 & 0 \\
\hline 1978 & 96.000 & 60.000 & 156.000 & 25,3 & 161,8 \\
\hline 1979 & 35.330 & 242.884 & 278.214 & 47,8 & 171,8 \\
\hline 1980 & 172.521 & 120.005 & 292.526 & 177,4 & 606,4 \\
\hline 1981 & 151.987 & 25.226 & 177.213 & 78,4 & 442,5 \\
\hline 1982 & 57.913 & 233.406 & 293.319 & 55,8 & 190,1 \\
\hline 1983 & 62.028 & 240.579 & 302.607 & 67,7 & 227 \\
\hline 1984 & 61.945 & 121.035 & 182.980 & 37,1 & 202,9 \\
\hline 1985 & 41.250 & 253.684 & 308.934 & 37,7 & 124,74 \\
\hline $1986(1)$ & 33.000 & 220.000 & 253.000 & 48,5 & 191,69 \\
\hline
\end{tabular}

(1) Los datos para 1986 son estimaciones.

Fuente: N.N., La industria azucarera en Colombia, p. 8, AHLM, Caja 39, carpeta 4

el cual se producen de forma simultánea energía eléctrica y térmica. (...) La cogeneración involucra generación de calor y de electricidad vinculado directamente a un proceso productivo, el cual se sirve de ambas formas de energía" (Informe Anual de Asocaña, 2012-2013, pp. 54 y 57).

Un estudio en 2003 encontró que la cogeneración podía aumentar la energía hasta una cifra entre 100-140 Mw, lo que aportaría un excedente de energía que se podría integrar a la red de interconexión eléctrica nacional. ${ }^{30}$ El sistema de cogeneración siguió desarrollándose y para 2012 el sector azucarero contaba con

\footnotetext{
${ }^{30}$ Cogeneración en el sector azucarero aplicando el enfoque ESCO, Proyecto PNUD-Asocaña, Ministerio de Medio Ambiente, upme, 2003.
} 
una capacidad instalada de cogeneración de 185 mw, lo que generó excedentes de electricidad que se vendieron a la red eléctrica nacional (Informe Anual Asocaña, 2012-2013, p. 57). El 12 de diciembre de 2013 el Congreso de Colombia aprobó la Ley 278 de 2013 por medio de la cual se regula la integración de las energías renovables no convencionales al Sistema Energético Nacional.

En Colombia hay 22 plantas de autogeneración y 21 plantas de cogeneración ubicadas en 12 departamentos del país, de las cuales 12 son del sector azucarero del Valle del Cauca. En cogeneración la capacidad total instalada es de 425 Mw de los cuales el 59\% corresponde a la capacidad de los ingenios azucareros del Valle. ${ }^{31}$

\section{B. Las exportaciones de la industria azucarera del Valle del Cauca}

El sector azucarero exportó modestas cantidades de azúcar de manera irregular entre las décadas de 1960 y 1970, puesto que debió sortear dificultades derivadas de la política económica de sustitución de importaciones, dominante desde el fin de la Segunda Guerra Mundial. En ese entonces se crearon organismos de intervención estatal, como el Instituto de Mercadeo Agropecuario (IDEMA) (1968), a través del cual el Estado regulaba todo lo relativo a los precios internos, y las exportaciones debían ser autorizadas y aprobadas por el Ministerio de Agricultura, para no poner en riesgo el abastecimiento interno. ${ }^{32}$

Entre 1979 y 1982 se inició el desmonte del control de precios y la política de exportaciones se hizo más flexible. Sin embargo, los precios del azúcar en el mercado exterior eran muy variables, como se observa en el Cuadro 10. El mercado más apetecido para las exportaciones era el de Estados Unidos, que asignaba una cuota fija a países azucareros, y pagaba mejores precios; Colombia tenía en ese entonces una cuota básica de 33.000 toneladas, que consideraba subestimaba su capacidad de producir excedentes, por lo que los dueños de ingenios llevaron a cabo un intenso cabildeo tanto en Estados Unidos como en Colombia durante años con el fin de incrementar esa cuota, sin conseguir avanzar significativamente.

\footnotetext{
${ }^{31}$ Estudio realizado por la "Cámara de Grandes Consumidores de Energía y Gas", de la ANDI, citado en el Informe Anual de Asocaña, 2014, p. 63.

${ }^{32}$ Los más recientes textos sobre la política económica de Colombia en este período son Caballero (2016), Urrutia (2015) y Kalmanovitz (2010).
} 
El resto del azúcar de exportación se vendía al mercado mundial a los precios del momento.

No fue sino hasta 1991, con el gobierno neoliberal de César Gaviria, que se pasó a una política económica de mercado abierto y de internacionalización de la economía. A partir de la década de 1990 las exportaciones de los excedentes de los ingenios cobraron mayor significación, como se puede ver en el Gráfico 5. Allí se ofrece un contraste del volumen de ventas, entre 1992 y 2003, en el que la cuota de exportación de azúcar a Estados Unidos, asignada a Colombia, es mínima frente a las exportaciones al mercado mundial y a la Comunidad Andina de Naciones. Las exportaciones a Estados Unidos eran las más cotizadas, como ya se dijo antes, por el más alto precio del azúcar en ese mercado, superior al del mercado mundial.

Entre 2002 y 2013, el grueso de la producción azucarera se vendió en el mercado interno, como se puede apreciar en el Grafico 6, que compara las exportaciones y el consumo interno para ese periodo.

\section{GRÁFICO 5}

Colombia: Exportaciones de azúcar por mercados, 1992-2003

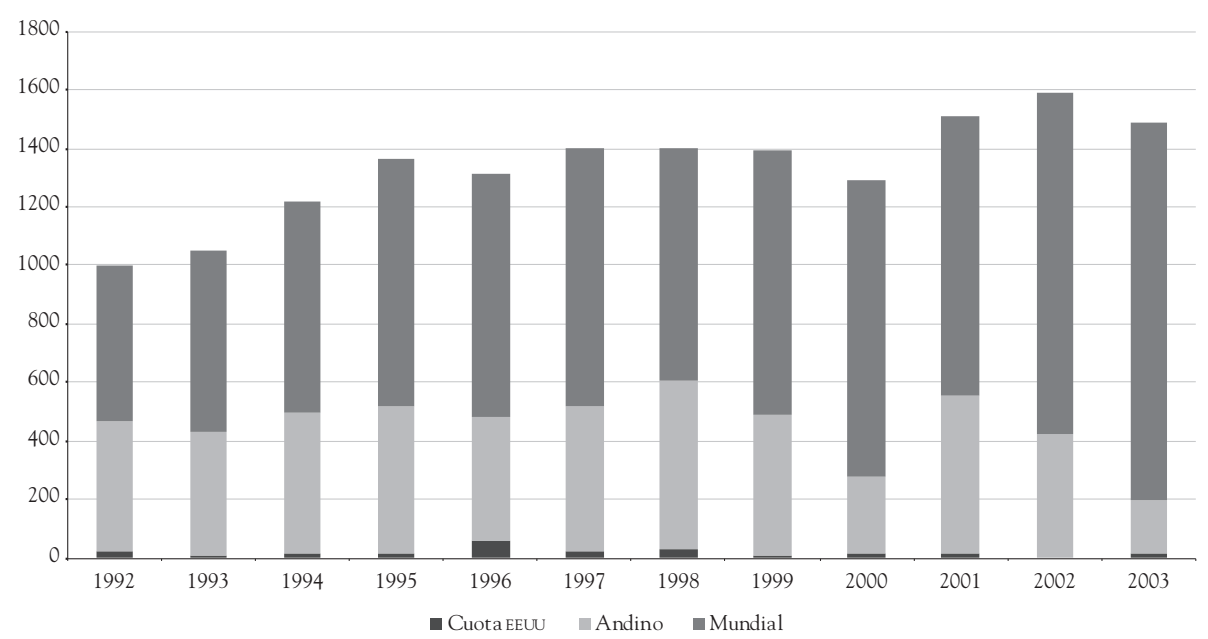

Notas: (1) La información corresponde a todos los ingenios.

(2) tmvc: Toneladas Métricas Valor Crudo

Fuente: Asocaña. 


\section{GRÁFICO 6}

Colombia: Distribución de las ventas de azúcar entre mercado nacional y exportaciones, y producción total y ventas, en US\$

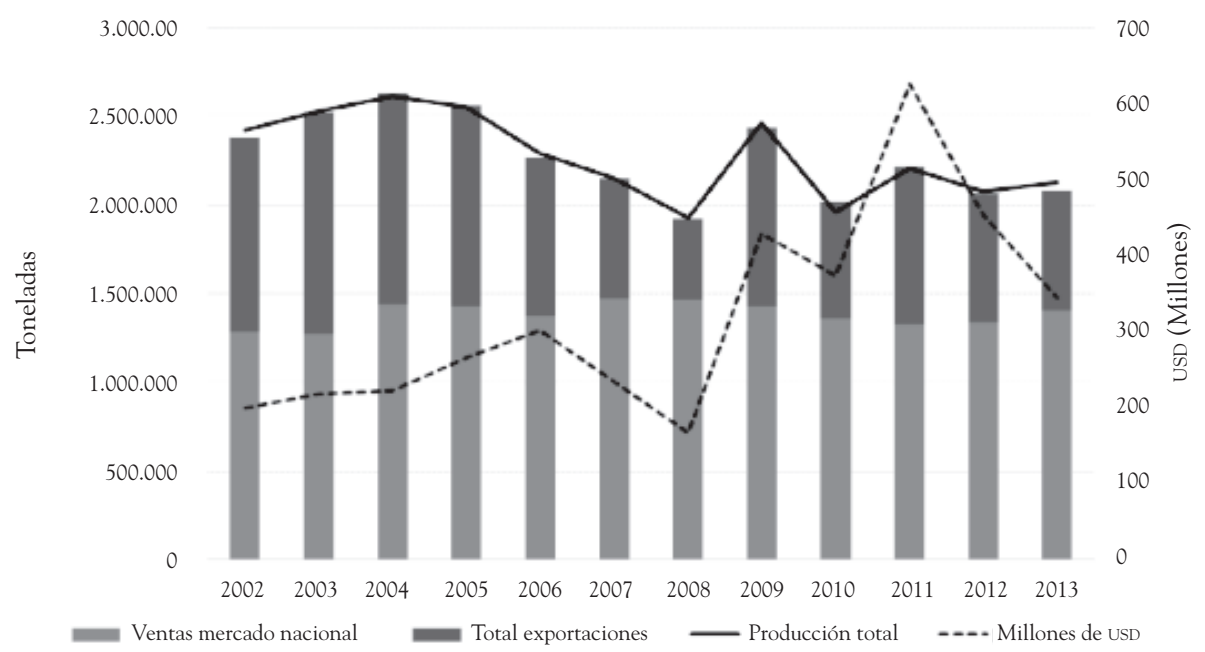

Notas: (1) La información corresponde a todos los ingenios.

(2) tmvc: Toneladas Métricas Valor Crudo

Fuente: Asocaña, Informe Anual 2012-2013.

\section{Un adecuado manejo ambiental}

Tanto la producción de biocombustibles como la coogeneración de energía son programas que han recibido incentivos del gobierno nacional desde la década de 1990 que contribuyeron al incremento del área sembrada en cultivos de caña de azúcar en el Valle del Cauca. Esta ampliación de la frontera agrícola en el valle del río Cauca ha suscitado algunos interrogantes entre ambientalistas, quienes en un estudio sobre el tema ${ }^{33}$ se preguntan si esos territorios están en capacidad de proveer los recursos naturales (el agua y la tierra) necesarios, y el adecuado manejo ambiental que requiere la intensificación de la actividad agrícola en este Valle que ya concentra más del 90 por ciento de la producción azucarera del país.

\footnotetext{
${ }^{33}$ Véase Pérez, Peña, y Álvarez (2011).
} 
En el caso del agua, en el estudio citado se hace referencia a los efectos que ha tenido el constante incremento de los cultivos de caña sobre el recurso hídrico, como el aumento de la apropiación del agua por parte de los cultivadores de la caña, con efectos contaminantes en el agua y los suelos, causados según este estudio, por el uso intensivo de fertilizantes y pesticidas químicos.

La conservación del medio ambiente es un tema que no ha dejado de preocupar al sector azucarero del Valle, al que destina una inversión anual (ver Cuadro 11). En cuanto al uso y el abuso de las fuentes de agua de la región, el sector azucarero ha llevado a cabo un programa compensatorio de conservación de las cuencas hidrográficas del valle geográfico del río Cauca que tiene como área de influencia directa las laderas de la cordillera, en un área aproximada de 750.000 hectáreas

\section{CUADRO 11}

Inversión en medioambiente y en investigación del sector azucarero, 2002-2013

\begin{tabular}{|c|c|c|}
\hline Año & $\begin{array}{c}\text { Inversión ambiental } \\
\text { (millones de pesos 2013) }\end{array}$ & $\begin{array}{c}\text { Presupuesto Cenicaña } \\
\text { (millones de pesos 2013) }\end{array}$ \\
\hline 2003 & 27.500 & 13.113 \\
\hline 2004 & 27.520 & 11.591 \\
\hline 2005 & 36.038 & 12.060 \\
\hline 2006 & 69.891 & 14.873 \\
\hline 2007 & 22.825 & 12.103 \\
\hline 2008 & 20.798 & 10.274 \\
\hline 2009 & 52.074 & 18.366 \\
\hline 2010 & 55.485 & 16.896 \\
\hline 2011 & 47.298 & 20.240 \\
\hline 2012 & 53.038 & 18.135 \\
\hline 2013 & 42.542 & 9.402 \\
\hline Total & 455.009 & 157.053 \\
\hline
\end{tabular}

Nota: La inversión ambiental 2005-2006 incluye el costo de las inversiones para el tratamiento ambiental de efluentes en las nuevas destilerías.

Fuente: Informe Anual Asocaña 2013-2014. Anexo Estadístico. 
comprendidas en un rango de altitud que va desde los 1.000 metros sobre el nivel del mar hasta los $4.200 \mathrm{msnm}$, zona en donde existen sistemas estratégicos de diversidad biológica que son muy importantes en la producción de agua. Este programa cuenta con el apoyo de la ONG, The Nature Conservancy, de la C.V.C., de las asociaciones de usuarios de ríos, de los cultivadores de caña, de Vallenpaz, Ecopetrol, de los campesinos de la región y de otros grupos de interés.

El azucarero es uno de los pocos gremios del país que creó un Departamento de Gestión Ambiental para el apropiado manejo de las fuentes de agua y de los residuos tóxicos. Resulta oportuno citar aquí las palabras del exministro de Medio Ambiente, Manuel Rodríguez Becerra, cuando afirmó, en la celebración de 50 años de Asocaña:

(...) el desempeño ambiental del sector azucarero es lo que uno quisiera ver en todo sector industrial en Colombia: que esté ajustado al cumplimiento de la Ley y que en algunos casos vaya más allá de lo que la Ley exige, que es la definición, naturalmente, de responsabilidad social empresarial, en este caso en el campo ambiental. (Informe Anual Asocaña, 2009-2010, p. 33).

Entre el 2003 y el 2013, el conglomerado agroindustrial del azúcar del Valle del Cauca invirtió tres veces más en el manejo ambiental de la zona que lo invertido en innovación y tecnología en el mismo período, según se observa en las cifras del Cuadro 11.

\section{A MANERA DE CONCLUSIÓN}

El sector azucarero del Valle del Cauca es uno de los complejos productivos de mayor influencia en el desarrollo económico y social de la región y del país. Ello se refleja en los datos de producción y rendimiento azucarero de La Manuelita, citados en este estudio, así como en la diversificación que ha experimentado su portafolio en el siglo XXI, y es el resultado del aprovechamiento de un conjunto de factores, naturales, políticos, institucionales, socioeconómicos, que se dieron en las distintas etapas que atravesó esta industria.

El grupo de productores del Valle conformó un tejido empresarial agroindustrial que se ha distinguido por algunos rasgos en común, entre los cuales sobresalen los siguientes: 
La importancia que los dueños de ingenios han dado, desde muy temprano, a la experimentación agrícola con distintas variedades de caña, lo que les generó muchas ventajas competitivas, entre las que sobresale una mayor productividad derivada de la siembra de variedades de caña con una mayor concentración de sacarosa. Hoy Colombia se distingue por la alta productividad de sus variedades de caña.

Un rasgo característico de los propietarios de ingenios del Valle es su capacidad de asociación para asumir y compartir riesgos en situaciones específicas que requerían del apoyo y del aporte colectivo de la producción de azúcar. Es así como el desplome de los precios durante la crisis de 1930 la asumen agrupándose, inicialmente bajo la Seccional de Crédito Azucarero, y entre 1938-1968 bajo la Compañía Distribuidora de Azúcares, para la equitativa distribución del mercado interno y la estabilización del precio. Se asociaron también en la creación de nuevos ingenios, para el incremento de la producción regional, como sucedió con el Ingenio Central Tolima, en Pajonales, y el Ingenio del Cauca. Se asocian en empresas innovadoras, como Sucroquímica, en la producción de derivados de acetaldehídos, y en Colombiana de Mieles, una compañía exportadora de las mieles residuales de los ingenios con mercado en Estados Unidos.

A partir de la década de 1990, el modelo económico de apertura adoptado por el gobierno de Cesar Gaviria fomentó las exportaciones de productos básicos. De nuevo, los ingenios del Valle del Cauca se organizaron para exportar como una sola entidad. Los Estados Unidos asignaron a Colombia una cuota minima de sus importaciones de azúcar, lo que unió de nuevo a los propietarios de ingenios para financiar un intenso cabildeo ante las autoridades de ese país..

Los dueños de ingenios del Valle han sido innovadores al incorporar nuevas tecnologías en sus procesos de producción con el fin de adaptarse a coyunturas internas y externas que se han presentado en la producción azucarera, en Colombia y el mundo. En los últimos años han diversificado el portafolio de inversiones en nuevas industrias, en distintas regiones colombianas y en otros países de América Latina, con el fin de agregar valor a los subproductos de la caña, y también para evitar la excesiva dependencia del azúcar.

El desempeño de estos empresarios agroindustriales contrasta con la poca importancia que se le ha dado al tema del agro en los centros de educación superior en Colombia. Ninguna de las universidades privadas sobresalientes del país tiene programas de agronomía en su oferta programática, un sector que es vital en un país que como Colombia tiene aproximadamente 23 millones de hectáreas hábiles para la agricultura, de las cuales sólo 5.121 .508 eran cultivadas en 2016 ("Encuesta 
Nacional Agropecuaria", Portafolio, agosto 8 de 2017). Este trabajo aspira a contribuir a un mayor reconocimiento de los aportes positivos que en ese sentido ha hecho el sector azucarero del Valle del Cauca.

\section{REFERENCIAS}

Archivo Histórico de La Manuelita, Palmira, Valle del Cauca Informes Anuales de Asocaña

\section{Libros y capítulos en libros}

Almario García, O (2013, primera edición 1994), La configuración moderna del Valle del Cauca, 1850-1940. Espacio, poblamiento, poder y cultura. Popayán: Editorial Universidad del Cauca.

Arias, Ricardo (2011), Historia de Colombia contemporánea, 1920-2010, Bogotá: Ediciones Uniandes.

Balmori, Diana, Voss, S., Wortman, M (1990), Las alianzas de familia y la formación del país en América Latina, México: F.C.E.

Bejarano, J. A (1984), "La economía", Manual de Historia de Colombia, Vol. III, Bogotá: Procultura, Tercer Mundo Editores.

Bushnell, D (1995), Colombia, una nación a pesar de sí misma, Bogotá, Editorial Tercer Mundo.

Caballero Argáez, Carlos (2015), “El proceso económico”, en Eduardo Posada, y Deas, M. (director y coordinador), Colombia. Mirando hacia dentro, América Latina en la Historia contemporánea, Tomo 4, Mapfre, Taurus, Penguin Random House

Caballero A., Carlos (2016), La economía colombiana del siglo xx. Un recorrido por la historia y sus protagonistas, Bogotá: Penguin Random House.

Caicedo, Hernando (1965), Ensayos económicos y sociales, Cali: Editorial Norma.

Cassalet, D.C., Torres, A., Isaacs E., C.H (Editores) (1995), El cultivo de la caña en la zona azucarera de Colombia. Cali: Cenicaña, consultado en línea el 19 de febrero de 2016.

Castro de Posada, Beatriz (compiladora y editora) (1986), Ensayos selectos de Antonio J. Posada, Cali: Editorial Feriva.

Castro, Beatriz, (2010), "La agroindustria en Palmira y el ingenio Manuelita", Los Sueños Palmiranos, No. 9, abril. 
Cerutti, Mario (2006), "La construcción de una agrociudad en el noroeste de México. Ciudad Obregón (1925-1960)”, en Carrillo R., Arturo y Cerutti, M. (coordinadores), Agricultura comercial, empresa y desarrollo regional en el noroeste de México, México: Conacyt.

Dávila L., Carlos (2012), Empresariado en Colombia: perspectiva histórica y regional, Bogotá: Universidad de los Andes.

Dávila L., Carlos et al (2014), Historia de la investigación de mercados en Colombia. Trayectoria empresarial de Napoleón Franco, Bogotá: Universidad de los Andes.

Davis, John A., et al (1997), Generation to Generation. Life Cycles of the Family Business, Boston: Harvard Business School Press.

Eder, Phanor (1959), El Fundador Santiago M. Eder. Recuerdos de su vida y acotaciones para la historia económica del Valle del Cauca, Bogotá: Antares Ltda.

Fadul, Miguel y Peñalosa, Enrique (1962), La industria azucarera en Colombia, Asocaña, Cali.

Guardiola M., J (1995), “Avances tecnológicos entre 1950 y 1980”, en El cultivo de la caña en la zona azucarera de Colombia, Cali: Cenicaña. Consultado en línea en febrero de 2016.

Inga calle, Juan Carlos (2003), Industria azucarera peruana, evolución y perspectiva. Tesis de grado de Economía, Universidad de Piura, Perú. Consultado por internet: pirhua.udep.edu.pe en diciembre 18 de 2018.

Jackson, Gayle Pendleton W (1972), Making Policy in a Latin American Bureaucracy: The Cauca Valley Corporation of Colombia, Ph.D. Thesis, Washington University, Political Science. (Mecanuscrito).

Kalmanovitz, Salomón (2001), Las instituciones y el desarrollo económico en Colombia, Bogotá: Editorial Norma.

Kalmanovitz, Salomón, editor, (2010), Nueva historia económica de Colombia, Bogotá: Taurus/Universidad Jorge Tadeo Lozano.

Luna González, C.A., Cock, J.H., Palma, A. E., Diaz, L.V. y Moreno, A (1995), "Análisis de la productividad en la agroindustria azucarera de Colombia y perspectivas para aumentarla”, en El cultivo de la caña en la zona azucarera de Colombia. Cali: Cenicaña. Consultado en línea en febrero de 2016.

Mejía P., E (2002), "Ciro Molina Garcés y Carlos Durán Castro: gestores y científicos en el desarrollo agropecuario del Valle del Cauca”, en Dávila L., C. (compilador). Empresas y empresarios en la historia de Colombia. Una colección de estudios recientes, Vol. II, Bogotá: Uniandes, Cepal, Grupo Norma. pp. 1189-1214.

Mina, M. (seudónimo de Michael Taussig y Anna Rubbo) (1973), Esclavitud y libertad en el valle del río Cauca. Bogotá: Publicaciones La Rosca. 
Ocampo, José Antonio (2007, primera ed. 1984), "El surgimiento de Cali como centro industrial”, en Ocampo, José Antonio y Montenegro, Santiago, Crisis mundial, protección e industrialización, Bogotá: Editorial Norma.

Ocampo, José Antonio, Joaquín Bernal, Mauricio Avella, y María Erráziriz (1994), "La consolidación del capitalismo moderno (1945-1986)", en Ocampo (compilador), Historia económica de Colombia, Bogotá: Tercer Mundo, Fedesarrollo.

Posada Carbó, Eduardo (director) (2015), Colombia. La búsqueda de la democracia. América Latina en la historia contemporánea, Tomo 5, España, Fundación Mapfre.

Posada, Antonio J. y Jeanne de Posada (1966), C.V.C., un reto al subdesarrollo y al tradicionalismo, Bogotá: Tercer Mundo.

Poza, Ernesto (2010), Family Business, Canadá, Cengage Learning.

Ramírez, María Teresa (2015), "El proceso económico", en Posada Carbó, Eduardo, (Coord.), Colombia. La apertura al mundo, Tomo 3, América Latina en la Historia contemporánea, pp. 137-199.

Ripoll, María Teresa (2007), "El Ingenio de Sincerín, un intento de modernización en el Caribe colombiano", Empresarios centenaristas en Cartagena. Cuatro estudios de caso, Bogotá: Ediciones Unitecnológica, pp. 29-71.

Rojas G., José M (1983), Sociedad y economía en el Valle del Cauca. Tomo v, Bogotá: Biblioteca del Banco Popular, Universidad del Valle.

Romero I., María Eugenia (2009), "La industria azucarera de México. Historia, características, problemas y estrategias empresariales”, en Cerutti, Mario (coordinador). Hecho en México. Tres estudios recientes de historia empresarial mexicana, Bogotá: Monografías de Administración, Universidad de los Andes.

Tortolero V., Alejandro (1995), De la coa a la máquina de vapor. Actividad agrícola e innovación tecnológica en las haciendas mexicanas, 1880-1914. Siglo XXI.

Urrutia, Miguel (2015), “El proceso económico”, en Eduardo Posada Carbó, editor, Colombia. La búsqueda de la democracia, Madrid: Mapfre/Taurus.

Urrutia, Miguel (2017), Historia del sindicalismo en Colombia, 1850-2013, Bogotá: Ediciones Uniandes, Universidad de los Andes, Bogotá. (Primera edición en 1969).

Zanetti, O (2012), Esplendor y decadencia del azúcar en las Antillas hispanas, La Habana: Editorial de Ciencias Sociales.

Zegarra M., Eduardo (2004), La industria azucarera peruana en el contexto internacional y la posible firma del TLC con los Estados Unidos, Perú: Ministerio del Comercio Exterior y Turismo.

Zuluaga, Francisco U., Mejía, Eduardo, Valencia, Rosángela, Arias, Alexander (2014), Manuelita 150 años, Cali: Feriva. 


\section{Artículos en revistas}

Cepal (2009), La crisis en los precios del petróleo y su impacto en los países centroamericanos, NU, CEPAL, 128 páginas. Documento consultado en 18 julio 2016 en LCmexL908_es.pdf

McCook, Stuart (2001), "Promoting the 'Practical': Science and Agricultural Modernization in Puerto Rico and Colombia, 1920-1940", Agricultural History, Vol. 75, No. 1, Winter, 2001, pp. 52-82. http://www.jstor.org/stable/3744921. Consultada 21/02/2016.

Mejía A (2011), "Agrofuels policy in Colombia: Expectations and rural development”, Agronomía Colombiana, 29 (1), pp. 133-140. http//search.proquest. com/doc view/677583863?accountid=15412 Consultado el 8 de abril 2016.

Millán, F (Coord.) (2002), El conglomerado del azúcar del Valle del Cauca, Colombia. Serie Desarrollo Productivo, No. 134, CEPAL/ECLAC, Santiago de Chile.

Pérez, M.A., Peña, M.R. y Álvarez, P (2011), "Agroindustria cañera y uso del agua: Análisis crítico en el contexto de la política de agrocombustibles en Colombia”, Ambiente EO Sociedad, 14, (2), pp. 153-178. Consultado en línea bajo www. scielo.br/pdf/asoc/v14n2/11.pdf

Rojas, Diana Marcela (2010), La Alianza para el Progreso de Colombia, Análisis político, Vol. 23, No. 70, Bogotá. (Investigadora del IEPRI, Universidad nacional de Colombia), sept./dic.

Toasa, J (2009), Colombia: A New Ethanol Producer on the Rise? United States Department of Agriculture, Economic Research Service, www.ers.usda.gov. Consultado en línea en mayo 2016.

Cogeneración en el sector azucarero aplicando el enfoque ESCO (2003), Proyecto PNUD-Asocaña, Ministerio de Medio Ambiente, UPME.

\section{Prensa periódica}

Portafolio

La República

El Tiempo

Revista Semana

Ávila Pinto, R (2016), "Frente a una dulce compañía”, Portafolio, 18 mayo 2016, pp. 30-35.

Espinoza F., A (2016), “¿Exportar o producir etanol?”, Portafolio, 18 mayo 2016, página editorial. 
Redacción del periódico (2016), "La planta de piña de Riopaila exportará 700 contenedores”, Portafolio, 9 junio 2016, p. 6.

Ricardo Villaveces (2016), "Cenicaña”, Portafolio, 31 de mayo 2016, p. 30.

Redacción del periódico (2016), "Si se abren las importaciones, las nuevas plantas de etanol no serán rentables", La República, 23 mayo 2016, p. 6.

Redacción del periódico (2016), "Precio del azúcar, a ritmo de la Niña y la oferta mundial”, La República, 10 junio 2016, p. 4.

Redacción del periódico (2016), "Valle y Cauca, una región de oportunidades", Separata especial de La República, 25 julio 2016, p. 16.

Redacción del periódico (2019), "Caña, energía y etanol: los activos de Bioenergy", Portafolio, 26 y 27 de enero de 2019.

\section{Informes especiales}

Asocaña (sin fecha), "Desarrollo de la industria azucarera colombiana, 1964 1968”, Cali. AHLM, Caja 17, carpeta 17.

Chardón, C. E (1930), Reconocimiento agropecuario del Valle del Cauca. Informe emitido por la Misión Agrícola Puertorriqueña dirigida por el Hon. Carlos E. Chardón y presentada al Gobernador del Departamento del Valle en Colombia. San Juan, Puerto Rico.

Hermes, A., Thorin C., L., y Obando, N (1938), Informe de la comisión encargada de visitar los ingenios azucareros del país. Bogotá: Ministerio de Economía Nacional, Mecanuscrito Cenicaña.

Samper Gnecco, A (sin fecha), "Establecimiento de Cenicaña 1977-1978: Una mirada retrospectiva a sus antecedentes, fundación y la selección de los programas prioritarios”, Documentos de Trabajo 5334, Cenicaña.

Informes Anuales de Asocaña, y sus Anexos Estadísticos, para todos los años comprendidos entre 1999 y 2016. Consultados en línea en www.asocana.org durante los meses de elaboración de este trabajo. 